\title{
Review of Historical Street Dust and Dirt Accumulation and Washoff Data
}

\author{
Robert Pitt, Derek Williamson, John Voorhees and Shirley Clark
}

Many complex models that utilize continuous simulation (SWMM, HSPF, SLAMM, SIMPTM, etc.) require information pertaining to the accumulation rate of pollutants on the land surfaces. This is one of the most perplexing issues in stormwater modeling. A representation of the accumulation rates is usually obtained through trial and error during calibration, with little, if any, actual direct measurements. Historically, direct measurements have been misapplied in modeling applications, resulting in unreasonable model predictions. Many modelers therefore forego accumulation rate data, preferring to back into values from outfall observations. This approach makes it very difficult to correctly predict the sources of stormwater pollutants in urban areas and to make reasonable stormwater management decisions using source area controls. This dilemma has come about due to a major misinterpretation of previously collected field data: the assumption that street dirt loadings are zero after most rains. With the correct understanding and modeling of the washoff process, the vast amount of historically collected accumulation data becomes an important modeling resource. This Chapter presents a summary of this useful information. This information has been used in Pitt and Voorhees' Source Loading and Management Model (SLAMM) and variations have been used in Sutherland's Simple Particulate Transport Model (SIMPTM) to more accurately predict these important source area processes. Relatively simple modifications can be made to other continuous models that utilize accumulation and washoff functions for more accurate and complete stormwater control predictions.

Pitt, R.E., D. Williamson, J. Voorhees and S. Clark. 2005. "Review of Historical Street Dust and Dirt Accumulation and Washoff Data." Journal of Water Management Modeling R223-12. doi:

10.14796/JWMM.R223-12.

(C) CHI 2005 www.chijournal.org ISSN: 2292-6062 (Formerly in Effective Modeling of Urban Water Systems. ISBN: 0-9736716-0-2) 


\subsection{Introduction}

Historically, the term "street dust and dirt" was applied to all items that are washed (or sampled) from streets. It actually includes both inert and volatile materials, including soils (usually the most abundant component), trash and litter (wood, paper, plastics, Styrofoam, metal, etc.), and organic matter (animal feces, grass clippings, leaves, etc.).

The earliest direct street dirt accumulation and washoff tests were conducted by Sartor and Boyd (1972) during their landmark EPA research project. They examined these as two separate components to enable more effective measurements for many different conditions. Others have examined street dirt accumulation and washoff as a combined process by examining runoff data from well described areas, and deriving accumulation and washoff rates by examining interevent data and rainfall characteristics. Unfortunately, this ignores many other processes that may affect the transport of stormwater particulates to the measurement locations, most notably run-on of material from adjacent areas and the deposition and scour of particulates in the drainage system. In addition, these tests are not controlled and the highly varying rain intensities tend to introduce much data scatter. This chapter therefore only examines the data separating the accumulation and washoff processes, as commonly utilized in many stormwater quality models. These models can have additional routines to specifically examine deposition and scour in the drainage system. If the outfall-derived accumulation and washoff data was used in these models, inaccurate and confusing results are often predicted.

\subsection{Methodology for Street Dirt Accumulation Measurements}

The street dirt sampling procedures used to collect most of the data summarized in this chapter were developed by Pitt (1979) and were extensively used during many of the EPA's Nationwide Urban Runoff Program (NURP) projects (EPA 1983) and other street cleaning performance studies and washoff studies (Pitt 1987). These procedures were developed to be much more flexible and more accurate indicators of street dirt loading conditions than previous sampling methods used during earlier studies (such as Sartor and Boyd 1972, for example). Powerful dry vacuum sampling, as used in this sampling procedure, is capable of removing practically all of the 
particulates ( $>99 \%)$ from the street surface, compared to wet sampling. It can also remove most of the other major pollutants from the street surface $(>80 \%$ for COD, phosphates and metals, for example). Wet sampling (used by Sartor and Boyd 1972), better removes some of the constituents, but wet sampling is restricted to single, small area sampling and therefore results in poorer descriptions of the street dirt characteristics due to limited samples and poor representativeness. Dry sampling can be used in many locations throughout an area, is fast, and can also be used to isolate specific sampling areas (such as driving lanes, areas with intensive parking, and even airport runways and freeways, if special safety precautions are used). It is especially useful when coupled with appropriate experimental design tools to enable suitable numbers of subsamples to be collected representing subareas, and finally, the collected dry samples can be readily separated into different particle sizes for discrete analyses without the expense of additional wet samples.

One example of this sampling method was used by Pitt and McLean (1986) as part of the Humber River study portion of TAWMS (Toronto Area Watershed Management Study). An industrial street with heavy traffic and a residential street with light traffic in Toronto were monitored about twice a week for three months. At the beginning of this period, intensive street cleaning (one pass per day for each of three consecutive days) was conducted to obtain reasonably clean streets. Street dirt loadings were then monitored every few days to measure the accumulation rates of street dirt from those low levels. The methods used for collecting and handling the samples are described in detail in Burton and Pitt (2002), and in the early EPA reports (Pitt 1979).

\subsection{Other Accumulation and Washoff Data Sources}

Many other researchers have examined roadway washoff during actual rain events. As noted above, this information is difficult to use to derive accumulation and washoff rates that are needed in some models. However, these data do provide excellent insights and enable the washoff model predictions to be compared to actual runoff observations. The following list briefly mentions some of these more recent research studies that have examined roadway runoff.

- Wada and Miura (1996) examined storm runoff from a heavily traveled highway in Osaka, Japan. The primary factors affecting 
storm runoff concentrations were the amount of traffic and the fraction of the total traffic that was comprised of trucks and buses.

- Montrejaud-Vignoles, et al. (1996) collected storm runoff from a heavily used six-lane motorway in the Mediterranean area of France. The very irregular rainfall in this area and associated very-long dry periods can result in storm runoff that is much more polluted than elsewhere in France.

- Ball, et al. (1996) and Ball 2000 examined roadway pollutant accumulations in a suburb of Sydney, Australia. They found that local heavy winds had a significant effect on pollutant accumulations. Historical United States' data on roadway-pollutant accumulations are much greater than found in their area.

- Sansalone and Buchberger (1996) studied metal distributions in stormwater and snowmelt from a major highway in Cincinnati, $\mathrm{OH}$. $\mathrm{Zn}$ and $\mathrm{Cd}$ were mostly in filterable (dissolved solids) forms in the storm runoff, while lead was mostly associated with particulates. Sansalone has more recently examined highway runoff from Baton Rouge, LA.

- Sharma et al., (1997) used a receptor-source model to predict source contributions for PAHs in street and creek sediments. The model showed that vehicles, along with the coke ovens, are the major contributors to PAHs in street sediments.

- Downing and McGarity (1998) measured conductivity and turbidity in an urban creek in Philadelphia, Pa. They found two stages of pollutant discharges during the first three hours of wet weather runoff: a dissolved solids initial flush followed by a later suspended solids (SS) flush.

- Roger, et al. (1998) found that $90 \%$ of the particles from a contaminated highway runoff catchment were smaller than $100 \mu \mathrm{m}$ during a European study.

- Waschbusch, et al. (1999) investigated sources of phosphorus in stormwater and street dirt from two urban residential basins in Madison, Wisconsin. They collected numerous sheetflow runoff samples from throughout the test watersheds and concluded that lawns and streets contributed about $80 \%$ of the total annual loading.

- Andral, et al. (1999) analyzed runoff sediments to document total suspended solids, mineral content, and heavy metals in the Kerault Region of France. 
- Dierkes and Geiger (1999) found that runoff from German highways contains significant loads of heavy metals and hydrocarbons, and, according to German regulations, it should be treated prior to being used for groundwater recharge.

- Drapper, et al. (2000) examined pollutant concentrations (heavy metals, hydrocarbons, pesticides, and physical characteristics) in "first flush" road runoff in Brisbane in southeast Queensland, Australia. Traffic volumes were the best indicator of road runoff pollutant concentrations, with interevent durations also being a statistically significant factor. Particle sizing showed significant proportions of the sediment in runoff were less than $100 \mu \mathrm{m}$.

- Krein and Schorer (2000) found an inverse relationship between particle size and particle-bound heavy metal concentrations in road runoff, while particulate-bound PAHs were found to be bimodally distributed.

- Sutherland, et al. (2000) investigated the potential for road-deposited sediments in Oahu, Hawaii, to bind contaminants, and thus transport these bound contaminants to the receiving water as part of the runoff.

- Stenstrom, et al. (2001) studied freeway runoff from three sites in the west Los Angeles area. The data showed large first flushes in concentration and moderate first flushes in mass emission rates.

- Neary, et al. (2002) studied the pollutant washoff and loadings from parking lots in Cookeville, Tennessee, and found that the washoff was affected by antecedent dry conditions and rainfall intensity.

- Ma, et al. (2002) investigated first-flushes for highways. Most pollutants indicated that $30 \%$ of the mass is released in the first $20 \%$ of the runoff. Pollutants representing organic contaminants had the highest first flush ratios.

- Lau, et al. (2002) studied three highway sites and found first flushes for most parameters. The mass first flush ratio generally was above 1.8 for the first $25 \%$ of the runoff volume, and in some cases as high as 2.8 .

- Vaze and Chiew (2003) studied pollutant washoff from small impervious experimental plots and showed that the energy of the falling raindrops was important at the beginning of the event where the concentration/prevalence of easily detachable pollutants was greatest. 
- Kayhanian, et al. (2003) investigated the relationships between annual average daily traffic (AADT) numbers and highway runoff pollutant concentrations from California Department of Transportation highway sites. Multiple linear regression tests showed that AADT, as well as antecedent dry period, drainage area, maximum rain intensity and land use, influenced most highway runoff constituent concentrations.

- Mishra, et al. (2003) developed mass rating curves for runoff rate and mass of 12 dissolved and particulate-bound metal elements from Cincinnati, OH. Zinc was found to increase with antecedent dry period.

- Shinya, et al. (2003) evaluated the factors influencing highway pollutant loads associated with urban highway runoff. Particulates tended to be washed off in heavier rainfall. Antecedent dry period and traffic flow were not correlated with cumulative runoff load (except for TN).

- Sutherland (2003) investigated lead in six size fractions of roaddeposited sediment from Oahu, HI. Significant $\mathrm{Pb}$ concentrations were seen in all samples, with the silt plus clay fraction containing $38 \%$ of the total amount.

\subsection{Street Dirt Accumulation}

The washoff of street dirt and the effectiveness of street cleaning as a stormwater control practice are highly dependent on the available street dirt loading. Street dirt loadings are the result of deposition and removal rates, plus "permanent storage." The seasonal volatile components that decay also need to be considered. The most obvious example is seasonal leaf loadings. For a relatively short period in the fall, leaves can overwhelm all other street "dust and dirt" material. However, most cities have special cleaning operations that remove this material in a relatively short period. Initially, the large leaf loadings can create drainage hazards by clogging inlets. If not removed, this material decays, and is ground to smaller particles. As the leaves decay to smaller particles, they are more easily removed during rains. Microscopic examinations and other methods are used to identify the components of street dust and dirt. The density of street dust and dirt (after intact leaves and obvious grass clippings are removed) is usually in the range 
of 1.5 to $2.5 \mathrm{~g} / \mathrm{cm}^{3}$, reflecting the varying amounts of organic debris incorporated in the finer fractions of material.

The permanent storage component is a function of street texture and condition and is the quantity of street dust and dirt that cannot be removed naturally by rains or winds, or by street cleaning equipment. It is literally trapped in the texture, or cracks, of the street. The street dirt loading at any time is this initial permanent loading plus the accumulation amount corresponding to the exposure period, minus the re-suspended material removal by wind and traffic-induced turbulence. Removal of street dirt can occur naturally by winds and rain, or by human activity (e.g., by the turbulence of traffic or by street cleaning equipment). Very little removal occurs by any process when the street dirt loadings are small, but wind removal may be very large with larger loadings, especially for smooth streets (Pitt 1979).

It takes many and frequent samples to ascertain the accumulation characteristics of street dirt. One of the first research studies to attempt to measure street dirt accumulation was conducted by Sartor and Boyd (1972). The data from this research was used to form much of the core of some of the most commonly used stormwater models still being used. The primary purpose of this early EPA-funded research project was to investigate the role of street dirt as a water pollutant. Field investigations were conducted, between 1969 and 1971, in several cities throughout the US and in residential, commercial, and industrial land use areas. A major element of the field tests involved measuring the street dirt loadings on the streets. An appropriate test location was selected in each city and for each of the land uses. The test sites had to be near a fire hydrant because water was needed and in an area having no parked cars because access to the curbs was also required. Each area was

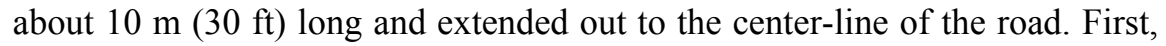
hand sweeping with a push broom was used to capture the large particulates. The sweeping action was from the center of the street towards the curb, and then along the curb where it was collected using a dust pan and the debris was placed in a new metal paint can. The area was then vacuumed using a wet-dry shop vacuum connected to a portable generator, and the collected street dirt was also transferred to the sample can. The street was then hosed down, again starting at the street centerline and moving towards the curb, then along the curb in a down-slope direction. A garden hose having an adjustable nozzle was used to form a forceful spray to the street. The hose was attached to an adapter and flow meter and connected to a nearby fire hydrant. The water was applied until the street stopped showing signs of foaming. The runoff was collected using the wet-dry shop vacuum. The collected water was then 
poured into appropriate Nalgene ${ }^{\circledR}$ sample bottles (after measuring the total water volume collected). The samples were then brought to a local hotel where a portable Millipore ${ }^{\circledR}$ bacteriological laboratory was used to analyze the samples for total and fecal coliforms. The remaining samples were then shipped to the analytical laboratory where the solids, metals, COD, and nutrients were analyzed in both the wet and dry sample fractions. The dry sample fractions were further sub-divided into separate particle sizes using standard laboratory sieves, ranging in size from $63 \mu \mathrm{m}$ to about $2,000 \mu \mathrm{m}$. A $6,370 \mu \mathrm{m}$ screen (made of $1 / 4$ inch "hardware cloth" attached to a wooden frame) was used before the sieves to remove the large debris, including stones, leaves, and litter. Each sieved fraction (including the screened material) was evaluated to determine the particle size distribution, and composites were made for chemical analyses.

During a follow-up study, Pitt and Amy (1973) further analyzed each particle size fraction for heavy metal content. The concentration data was converted to units of $\mathrm{lb} /$ curb-mile, based on the length of the gutter included in the test area. Prior efforts during this research had found that the street dirt loadings were un-evenly distributed across the street (the test sites were divided into narrow strips parallel to the curb and each strip was swept and vacuumed for separate analyses). More than $90 \%$ of the street dirt was found to be within $30 \mathrm{~cm}$ (one foot) of the curb during these strip tests. Other measurements conducted during this research included sampling adjacent test areas before and after street cleaning. Many other elements were also included in the breakthrough Sartor and Boyd (1972) research, including street dirt washoff tests that will be discussed later.

Figure 12.1 is a plot of the 26 test area measurements collected from different cities, but separated by the three land uses. The data were plotted based on the number of days since the street had been cleaned by the municipal street cleaning operation, or a "significant" rain. A significant rain was considered to be about $10 \mathrm{~mm}$, or larger, that occurred over a few hours. These rains normally remove at least $90 \%$ of the "available" street dirt washoff load, as will be described in the following discussion. The street cleaning and this rain were both assumed to remove all of the street dirt; hence the curves were all forced through zero loading at zero days.

During later street dirt measurements in the mid-1970s, Pitt (1979) modified the earlier street dirt sampling methods to allow better statistical representations throughout the test area and to not be restricted to areas having no parked cars. These modified street dirt sampling methods are described by Burton and Pitt (2002). 


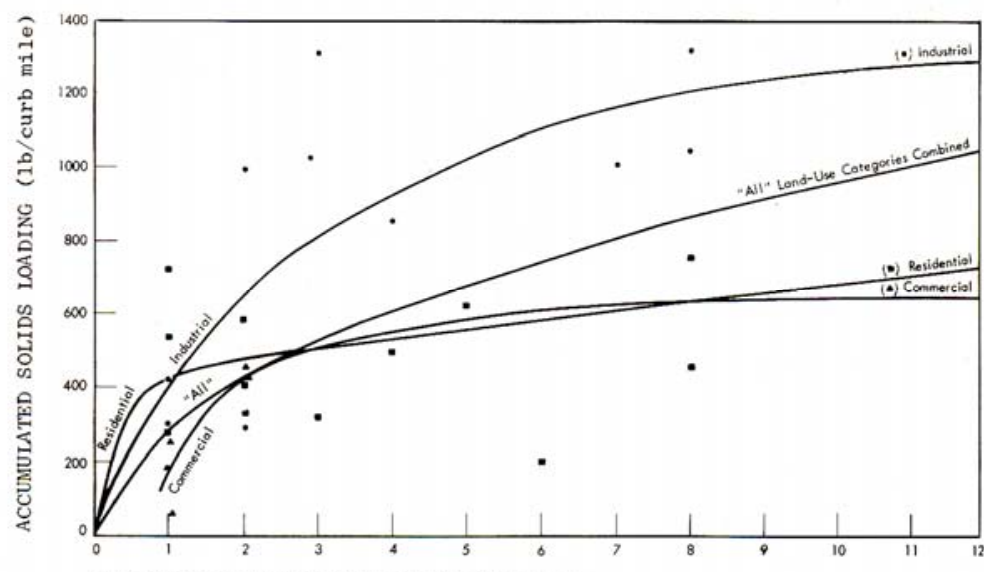

ELAPSED TIME SINCE LAST CLEANING BY SWEEPING OR RAIN (days)

Figure 12.1 Accumulation curves developed during early street cleaning research (Sartor and Boyd 1972).

The studies summarized in this Chapter typically involved collecting many hundreds of composite street dirt samples every few days during the course of the one to three year projects from each study area. With each composite sample made up of about 10 to 35 subsamples, a large number of subsamples were collected, typically numbering in the thousands per project. Without this high resolution (and effective) sampling, it is not possible to identify the variations in loadings and effects of rains and street cleaning on street dirt loadings. Figures 12.2 and 12.3 are examples of the measured street dirt loading as a function of time for both smooth and rough streets for an early study in San Jose, CA (Pitt (1979). These plots are for a short portion of the whole test period and only show results for a series using a standard 4-wheel mechanical street cleaner and the beginning of the next series using a newer unit. These plots do not show the results for the vacuum-assisted street cleaner which are given in the full research report. These plots clearly show accumulation rates (and increases in particle size of the street dirt) as time between street cleaning lengthens. It is also evident that there is a substantial residual loading on the streets immediately after the street cleaning (the "before" and "after" street dirt samples were collected immediately before and after the street cleaning operations, typically within a half hour).

Figure 12.4 shows very different street dirt loadings for two San Jose, CA residential study areas having different street textures (Pitt 1979). The accumulation and deposition rates are quite similar, but the initial loading 
values (the permanent storage values) are very different. The loading differences were almost solely caused by the different street textures, with greater amounts of street dirt trapped by the coarser (oil and screens) pavement. Street cleaning and rains are not able to remove this residual material, but effective sampling can.

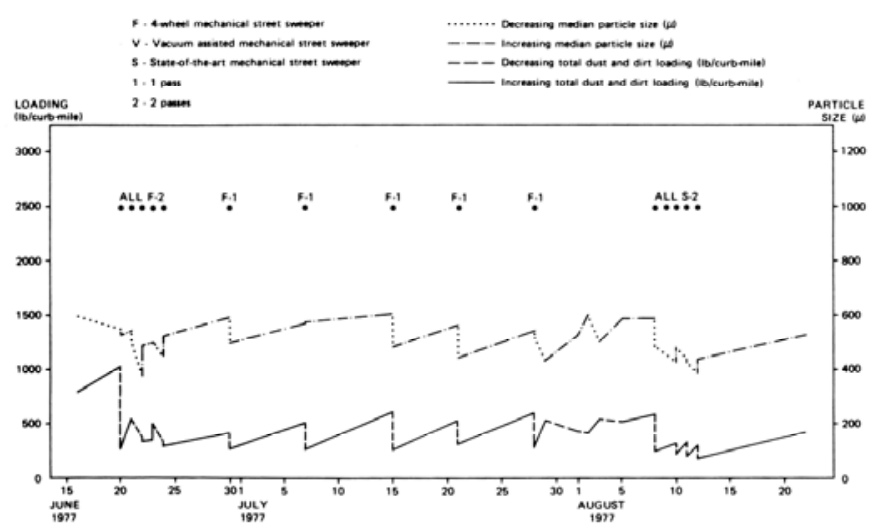

Figure 12.2 Street dirt accumulation and particle size changes on good asphalt streets in San Jose, CA (Pitt 1979).

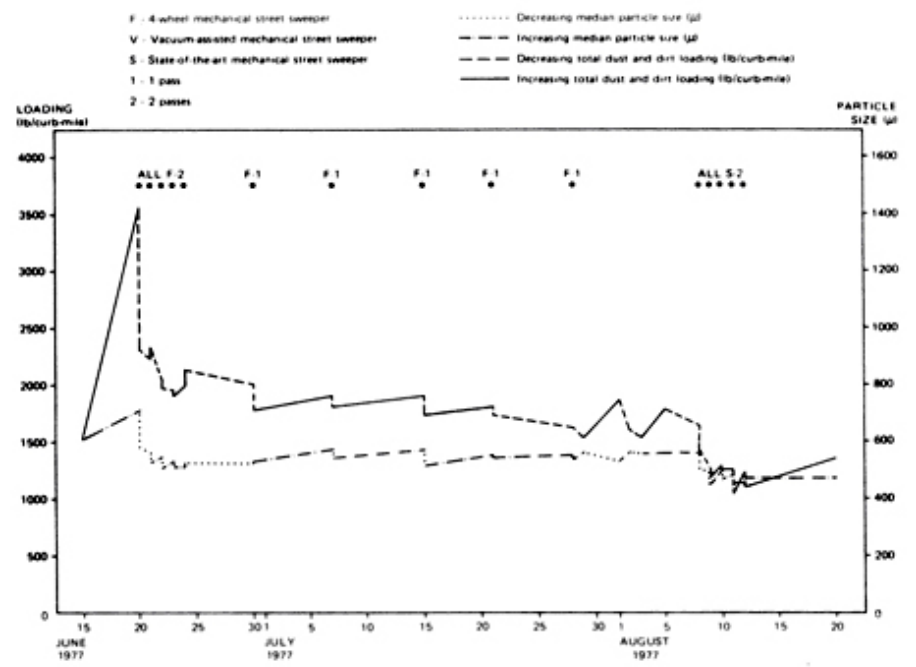

Figure 12.3 Street dirt accumulation and particle size changes on rough asphalt streets in San Jose, CA (Pitt 1979). 
"Oil and screens" is a common overlay material used to rejuvenate older road surfaces. A layer of oil is sprayed on the old asphalt and screens (small gravel that is screened to a specific size range) is then spread on the oil. The resulting surface is very rough, with substantial storage for finer materials.

In early studies (APWA 1969; Sartor and Boyd 1972; and Shaheen 1975), it was assumed that the initial loading values were zero. The sampling procedures used were very effective in removing all loose material from the streets, including the loadings that could not be removed by rains or street cleaning. Calculated accumulation rates for rough streets were therefore very large, as they were forced through the origin of the plot of the loading values against time. The early, uncorrected, Sartor and Boyd accumulation rates that ignored the initial loading values were almost ten times the corrected values that had reasonable "initial loads."

A street dirt loading equation that can be used to represent street dirt loading (Pitt 1979) is:

where:

$$
Y=a x-b x^{2}+c
$$

$$
\begin{aligned}
Y & =\text { street loading at time } x \\
a, b, c & =\text { second order polynomial curve coefficients } \\
a x & =\text { the deposition loading } \\
b x^{2} & =\text { the amount lost to the air, and } \\
c & =\text { the initial storage loading }
\end{aligned}
$$

This curve should only be used over the range of observed accumulation periods. For long accumulation periods, this quadratic equation may predict decreasing loadings, so the curve should only be extended until a maximum is reached.

At very long accumulation periods relative to the rain frequency, the wind losses (fugitive dust) may approximate the deposition rate, resulting in very little increases in loading. Roadside atmospheric particulate measurements were conducted by Pitt (1979) in San Jose as part of his street dirt measurement studies. He used Climet particle counters to obtain real-time size distributions of fugitive dust losses along busy roads as traffic and winds resuspended and transported the material off the streets and towards adjacent areas. Hi-volume samplers and meteorological stations were also simultaneously used to verify the mass measurements. In Bellevue, Washington, with interevent rain periods averaging about 3 days, steady loadings were observed only after about 1 week (Pitt 1985). In Castro Valley, California, the rain interevent periods were much longer (ranging from about 
20 to 100 days) and steady loadings were never observed (Pitt and Shawley 1982).

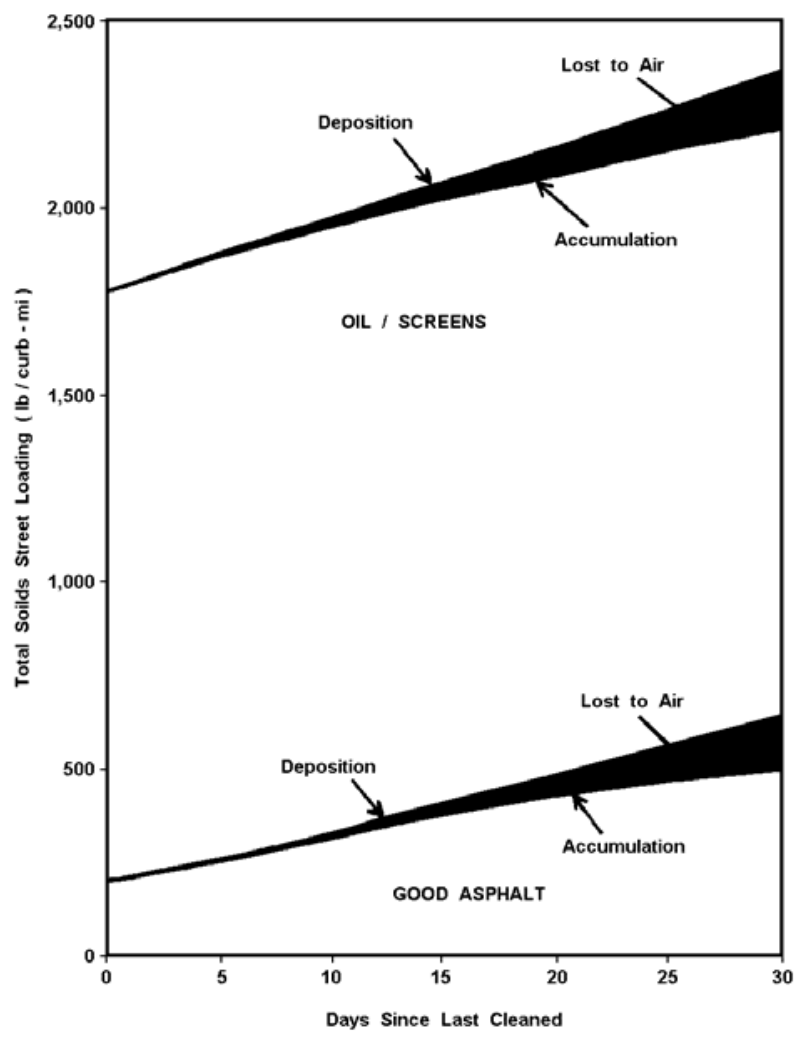

Figure 12.4 Deposition and accumulation of street dirt (Pitt 1979).

Street dirt loading data is difficult to fit to any curve because of many potential measurement and interpretation errors. The measurements are usually obtained with $25 \%$ allowable errors due to the large sampling effort increases needed to collect enough sub-samples to significantly reduce these errors. As an example, it requires about five times as many street dirt subsamples for a $10 \%$ allowable error as compared to a $25 \%$ allowable error (Pitt 1979). Many areas also have frequent (every few days) rains. In most cases, frequent rains keep the street dirt loadings very close to the initial storage value, with little observed increase in dirt accumulation over time. If 
the loading value is not very well correlated with accumulation time, linear regression curve fitting may not result in significant equation coefficients.

Other problems arise when attempting to use least squares regression techniques with data that contain different distributions of residuals (errors) over the range of predictor variables, or if the errors are not independent. This is especially true with street dirt accumulation data, as there are usually few street dirt loading observations associated with long accumulation periods. The shorter accumulation period observations usually have much smaller errors (due to smaller allowable data ranges) than the observations having longer accumulation periods (which are not as constrained). The short period loadings are relatively low, and the range of observed loadings at these low accumulation periods range from zero to values two or three times higher than the predicted loadings. The observed loadings at the longer accumulation periods are also constrained at zero for minimum values, but the range of possible values is much larger than for the lower loadings. The errors for these longer period observations can be greater because of the greater opportunity for other factors that are not included in the regression relationship to be prominent. These other factors include variable winds, traffic, and moisture conditions. If the data are extensive, then they may be separated into seasonal groupings to reduce the variations of these other factors. Logarithmic transformations of the loading values can sometimes produce normally distributed residuals over the range of data that are necessary for least-squares regression analyses. It is relatively easy to calculate the accumulation rate for the critical short time periods using data such as shown in Figures 12.2 and 12.3 which are numerous and highly repeatable. The fewer and more variable data associated with longer accumulation periods (long dry periods) are more difficult to analyze.

Early measurements of across-the-street dirt distributions made by Sartor and Boyd (1972) indicated that about $90 \%$ of the street dirt was within about $30 \mathrm{~cm}$ of the curb face (typically within the gutter area). These measurements, however, were made in areas of no parking (near fire hydrants because of the need for water for the sampling procedures that were used). The trafficinduced turbulence was therefore capable of blowing most of the street dirt against the curb barrier (or over the curb onto adjacent sidewalks or landscaped areas) (Shaheen 1975). In later tests, Pitt (1979) and Pitt and Sutherland (1982) examined street dirt distributions across-the-street in many additional situations. They found distributions similar to Sartor and Boyd's observations only on smooth streets, with moderate to heavy traffic, and with no on-street parking. In many cases, most of the street dirt was actually in the driving lanes, trapped by the texture of rough streets. If extensive on-street 
parking was common, much of the street dirt was found several meters out into the street, where much of the resuspended (in air) street dirt blew against the parked cars and settled to the pavement. Figure 12.5 shows across-thestreet distributions of street dirt, both before and after street cleaning for a relatively busy roadway (having no parking) in Bellevue, WA (Pitt 1985). Only about $20 \%$ of the street dirt was near the curb before street cleaning, while $90 \%$ was within about $2.5 \mathrm{~m}$. After cleaning, the load was even more evenly distributed, as the street cleaner preferentially removed street dirt near the curb and blew some dirt out into the street.

\subsection{Summary of Observed Accumulation Rates}

Table 12.1 summarizes many accumulation rate measurements obtained from throughout North America. In the earliest studies (APWA 1969; Sartor and Boyd 1972; and Shaheen 1975), the initial street dirt loading values after a major rain or street cleaning were assumed to be zero, as noted above.

Calculated accumulation rates for rough streets were therefore very large. Later tests measured the initial loading values close to the end of major rains and street cleaning and found that these initial values are usually high, depending on the street texture.

When these starting loadings were considered for the earlier measurements, the re-calculated accumulation rates were much lower. The early, uncorrected, Sartor and Boyd accumulation rates that ignored the initial loading values were almost ten times the corrected values shown on this table. Unfortunately, most urban stormwater models used these very high early accumulation rates as default values.

The most important factors affecting the initial loading and maximum loading values shown on Table 12.1 were found to be street texture and street condition, and not land use. When data from many locations are studied, it is apparent that smooth streets have substantially less loadings at any accumulation period compared to rough streets for the same land use. Very long accumulation periods relative to the rain frequency result in high street dirt loadings. During these conditions, the wind losses of street dirt (as fugitive dust) may approximate the deposition rate, resulting in relatively constant street dirt loadings.

In Castro Valley, CA, the rain interevent periods ranged from about 20 to 100 days, and steady loadings were observed after about 30 days when the 
loadings became very high and fugitive dust losses caused by the winds and traffic turbulence moderated the loadings (Pitt and Shawley 1982).

Pitt and McLean (1986) studied street dirt accumulation rates and the effects of street cleaning in Toronto. An industrial street with heavy traffic and a residential street with light traffic were monitored about twice a week for three months. The industrial area was relatively new (about 10 years old) and included about 100 separate operations, mostly warehousing but with some light manufacturing and some heavy equipment storage.

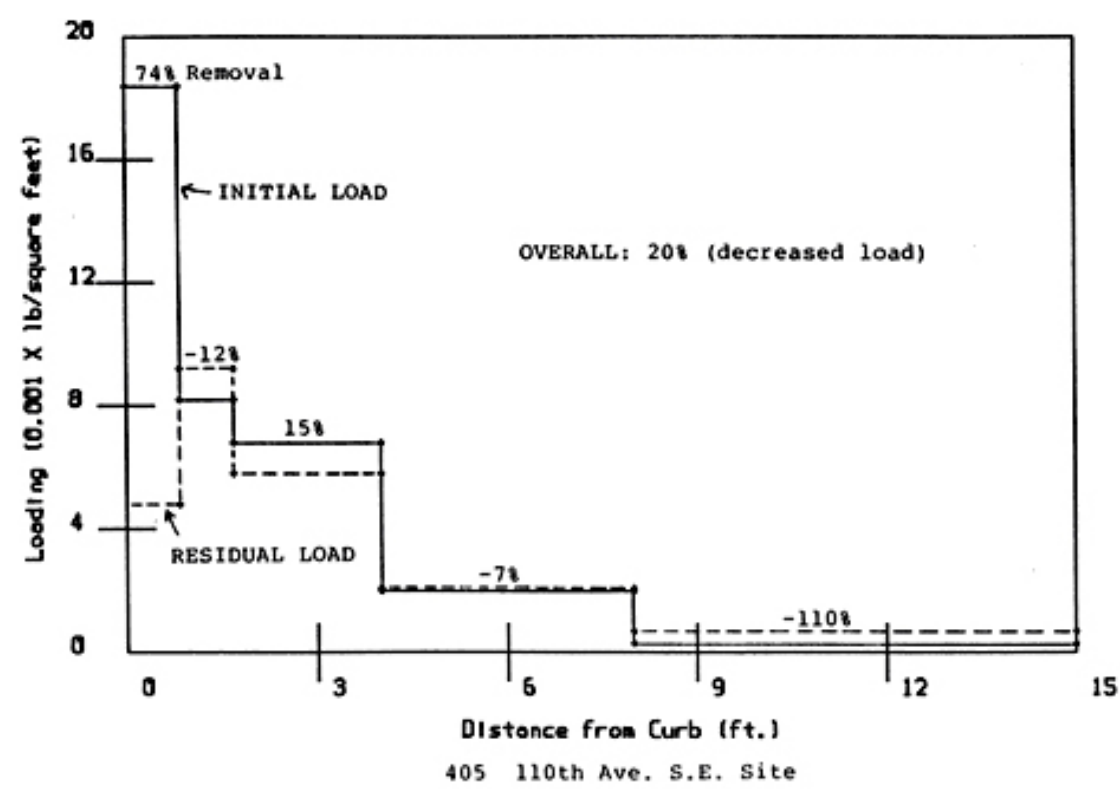

Figure 12.5 Re-distribution of street dirt across the street during street cleaning (Pitt 1985).

At the beginning of this period, intensive street cleaning (one pass per day for each of three consecutive days) was conducted to obtain reasonably clean streets. Street dirt loadings were then monitored every few days to measure the accumulation rates of street dirt. The street dirt particulate loadings were quite high before the initial intensive street cleaning period and were reduced to their lowest observed levels immediately after the last street cleaning. After street cleaning, the loadings on the industrial street increased somewhat faster than for the residential street. Right after intensive cleaning, the street dirt particle sizes were similar for the two land uses. However, the loadings of 
larger particles on the industrial street increased at a much faster rate than on the residential street, indicating more erosion or tracking materials being deposited onto the industrial street. The residential street dirt measurements did not indicate that any material was lost to the atmosphere as fugitive dust, probably because of the lower street dirt accumulation rate and the short periods of time between rains. The street dirt loadings never had the opportunity to reach the high loading values needed before they could be blown from the streets by winds or by traffic-induced turbulence. The industrial street, in contrast, had a greater street dirt accumulation rate and reached the critical loading values needed for fugitive dust losses in the relatively short periods between the rains.

\subsection{Washoff of Street Surface Pollutants}

\subsubsection{Background}

In many areas, the degradation of the road surface and traffic related discharges are responsible for most of the particulate discharges in urban runoff. This is true during relatively small and less intense rains. However, in areas having substantial exposed soil or dirt surfaces (including unpaved roads, driveways, or parking lots), these are also important sources. In addition, areas having substantial rain energies (such as in the US southeast) also have large sediment losses from landscaped areas, especially during larger storms when flows start to be produced from these areas.

Shaheen (1975) found that road surface particulates and polluted area soils (affected by traffic related pollutants) contribute most of the urban runoff particulate pollutants.

Many urban runoff models assume that "all" of the pollutants and runoff flows in urban areas originate from directly connected impervious areas, ignoring contributions from pervious areas. The correct interpretation of particulate washoff from impervious surfaces is therefore critical to understanding urban runoff quality. This discussion summarizes some of the procedures that are commonly used to estimate particulate washoff from impervious surfaces, presents the results of washoff tests, and describes a street dirt washoff model based on extensive field measurements. 
Table 12.1 Street dirt loadings and deposition rates.

\begin{tabular}{|c|c|c|c|c|c|}
\hline & 1 & 2 & 3 & 4 & Reference \\
\hline \multicolumn{6}{|l|}{ Smooth and Intermediate Textured Streets } \\
\hline Reno/Sparks, NV - good condition & 80 & 1 & 85 & 5 & $\begin{array}{l}\text { Pitt and Sutherland } \\
1982\end{array}$ \\
\hline $\begin{array}{l}\text { Reno/Sparks, NV - good with smooth } \\
\text { gutters (windy) }\end{array}$ & 250 & 7 & 400 & 30 & $\begin{array}{l}\text { Pitt and Sutherland } \\
1982\end{array}$ \\
\hline San Jose, CA - good condition & 35 & 4 & $>140$ & $>50$ & Pitt 1979 \\
\hline $\begin{array}{l}\text { U.S. nationwide - residential streets, } \\
\text { good condition }\end{array}$ & 110 & 6 & 140 & 5 & $\begin{array}{l}\text { Sartor and Boyd } 1972 \\
\text { (corrected) }\end{array}$ \\
\hline $\begin{array}{l}\text { U.S. nationwide - commercial street, } \\
\text { good condition }\end{array}$ & 85 & 4 & 140 & 5 & $\begin{array}{l}\text { Sartor and Boyd } 1972 \\
\text { (corrected) }\end{array}$ \\
\hline $\begin{array}{l}\text { Reno/Sparks, NV - moderate to poor } \\
\text { condition }\end{array}$ & 200 & 2 & 200 & 5 & $\begin{array}{l}\text { Pitt and Sutherland } \\
1982\end{array}$ \\
\hline $\begin{array}{l}\text { Reno/Sparks, NV - new residential area } \\
\text { (construction) }\end{array}$ & 710 & 17 & 910 & 15 & $\begin{array}{l}\text { Pitt and Sutherland } \\
1982\end{array}$ \\
\hline $\begin{array}{l}\text { Reno/Sparks, NV - poor condition, with } \\
\text { lipped gutters }\end{array}$ & 370 & 15 & 630 & 35 & $\begin{array}{l}\text { Pitt and Sutherland } \\
1982\end{array}$ \\
\hline San Jose, CA - fair to poor condition & 80 & 4 & 230 & 70 & Pitt 1979 \\
\hline Castro Valley, CA - moderate condition & 85 & 10 & 290 & 70 & $\begin{array}{l}\text { Pitt and Shawley } \\
1982\end{array}$ \\
\hline Ottawa, Ontario - moderate condition & 40 & 20 & na & na & Pitt 1983 \\
\hline $\begin{array}{l}\text { Toronto, Ontario - moderate condition, } \\
\text { residential }\end{array}$ & 40 & 32 & 100 & $>10$ & Pitt and McLean 1986 \\
\hline $\begin{array}{l}\text { Toronto, Ontario - moderate condition, } \\
\text { industrial }\end{array}$ & 60 & 40 & 351 & $>10$ & Pitt and McLean 1986 \\
\hline $\begin{array}{l}\text { Bellevue, WA - dry period, moderate } \\
\text { condition }\end{array}$ & 140 & 6 & $>230$ & 20 & Pitt 1985 \\
\hline Bellevue, WA - heavy traffic & 60 & 1 & 110 & 30 & Pitt 1985 \\
\hline Bellevue, WA - other residential sites & 70 & 3 & 140 & 30 & Pitt 1985 \\
\hline Average: & 150 & 9 & $>270$ & $>25$ & \\
\hline Range: & $\begin{array}{l}35- \\
710\end{array}$ & $1-40$ & $\begin{array}{c}85- \\
910\end{array}$ & $5-70$ & \\
\hline \multicolumn{6}{|l|}{ Rough and Very Rough Textured Streets } \\
\hline San Jose, CA - oil and screens overlay & 510 & 6 & $>710$ & $>50$ & Pitt 1979 \\
\hline Ottawa, Ontario - very rough & 310 & 20 & na & na & Pitt 1983 \\
\hline Reno/Sparks, NV & 630 & 10 & 860 & 35 & $\begin{array}{l}\text { Pitt and Sutherland } \\
1982\end{array}$ \\
\hline Reno/Sparks, NV - windy & 540 & 34 & $\begin{array}{r}>1,40 \\
0\end{array}$ & $>40$ & $\begin{array}{l}\text { Pitt and Sutherland } \\
1982\end{array}$ \\
\hline San Jose, CA - poor condition & 220 & 6 & 430 & 30 & Pitt 1979 \\
\hline Ottawa, Ontario - rough & 200 & 20 & na & na & Pitt 1983 \\
\hline \multirow[t]{3}{*}{$\begin{array}{l}\text { U.S. nationwide - industrial streets (poor } \\
\text { condition) }\end{array}$} & 190 & 10 & 370 & 10 & $\begin{array}{l}\text { Sartor and Boyd } 1972 \\
\text { (corrected) }\end{array}$ \\
\hline & 370 & 15 & $>750$ & $>30$ & \\
\hline & $\begin{array}{c}190- \\
630\end{array}$ & $6-34$ & $\begin{array}{c}370- \\
>1,40 \\
0\end{array}$ & $\begin{array}{l}10- \\
>50\end{array}$ & \\
\hline
\end{tabular}

1.Initial Loading Value (g/curb-m) 2. Daily Deposition Rate (g/curb-m-day) 3. Maximum Observed Loading (g/curb-m). 4. Days to Observed Maximum Loading 
Washoff of particulates from impervious surfaces is dependent on the available supply of particulates on the surface, the rain energy available to loosen the material, and the capacity of the runoff to transport the loosened material. Observations of particulate washoff during controlled tests may result in empirical washoff models that are not as limited as incomplete theoretical models. Washoff experiments using actual streets and natural street dirt and debris are affected by street dirt distributions and armoring. Their disadvantage is the assumption of transferability. If the washoff experiments are conducted for many situations, then it may be possible to use the resultant model for other situations.

Brief descriptions follow for two methods (the Yalin equation, as described and used by Sutherland and McCuen 1978, and the Sartor and Boyd, 1972, equation) currently used in most urban runoff models for estimating particulate washoff from impervious surfaces. They can be used to obtain satisfactory estimates of particulate washoff, if their limitations are recognized and if rough estimates are all that are required. Unfortunately, they are often used in situations beyond their limits (such as for small rains, unusual street dirt loadings, or rough pavement textures). Certain washoff equation parameters have also been misunderstood (such as confusing total street dirt load with "available" street dirt load). The use of these washoff equations in popular and well documented urban runoff computer models also implies more confidence in their accuracy than may be warranted.

A field study is also briefly summarized that found significant washoff differences for various particle sizes. These observed washoff quantities are compared to the values obtained with these two washoff models, but the observed washoff quantities are shown to be much less than predicted with these two washoff equations. These data observations and the existing washoff models' inabilities to accurately predict washoff lead to the series of washoff tests conducted by Pitt (1987) and the development of washoff models sensitive to important environmental conditions.

\subsubsection{Sartor and Boyd Washoff Equation}

The earliest controlled street dirt washoff experiments were conducted by Sartor and Boyd (1972) during the summer of 1970 in Bakersfield, California. Their data are used in many urban runoff models (including SWMM, Huber and Heaney 1981; STORM, COE 1975; and HSPF, Donigian and Crawford 1976) to estimate the percentage of the available particulates on the streets that would wash off during rains of different magnitudes. They used a rain 
simulator having many nozzles and a drop height of $1-1 / 2$ to $2 \mathrm{~ms}$ in street test areas of about 5 by $10 \mathrm{~ms}$. Tests were conducted on concrete, new asphalt, and old asphalt, using simulated rain intensities of about 5 and 20 $\mathrm{mm} / \mathrm{h}$. They collected and analyzed runoff samples every 15 minutes for about two hours for each test. Figure 12.6 shows two plots of their data, showing the asymptotic shape of the accumulative washoff curves for several particle sizes. Sartor and Boyd fitted their data to an exponential curve, assuming that the rate of particle removal of a given size is proportional to the street dirt loading and the constant rain intensity:

where:

$$
d N / d t=k r N
$$

$$
\begin{aligned}
d N / d t & =\text { the change in street dirt loading per unit time } \\
k & =\text { proportionality constant } \\
r & =\text { rain intensity }(\mathrm{in} / \mathrm{h}) \\
N & =\text { street dirt loading }(\mathrm{lb} / \text { curb-mile })
\end{aligned}
$$

This equation, upon integration, becomes:

where:

$$
N=N_{o} e^{-k r t}
$$

$$
\begin{aligned}
N & =\text { residual street dirt load (after the rain) } \\
N_{o} & =\text { initial street dirt load } \\
t & =\text { rain duration }
\end{aligned}
$$

Street dirt washoff is therefore equal to $N_{o}-N$. The variable combination $r t$, or rain intensity times rain duration, is equal to total rain volume $(R)$. This equation therefore further reduces to:

$$
N=N_{o} e^{-k R}
$$

Therefore, this equation is only sensitive to total rain, and not rain intensity. Because of decreasing particulate supplies, the exponential washoff curve predicts decreasing concentrations of particulates with time since the start of a constant rain (Alley 1980 and 1981).

It is very important to note that these figures did not show the total street dirt loading that was present before the washoff tests. Most modelers have therefore assumed that the asymptotic maximum shown was the total "beforerain" street dirt loading; the actual total street dirt loadings were several times greater than the maximum washoff amount observed. 
The proportionality constant, $k$, was found by Sartor and Boyd to be slightly dependent on street texture and condition, but was independent of rain intensity and particle size. The value of this constant is usually taken as $0.18 / \mathrm{mm}$, assuming that $90 \%$ of the particulates will be washed from a paved surface in 1 hour during a $13 \mathrm{~mm} / \mathrm{h}$ rain. However, Alley (1981) fitted this model to watershed outfall runoff data and found that the constant varied for different storms and pollutants, for a single study area.
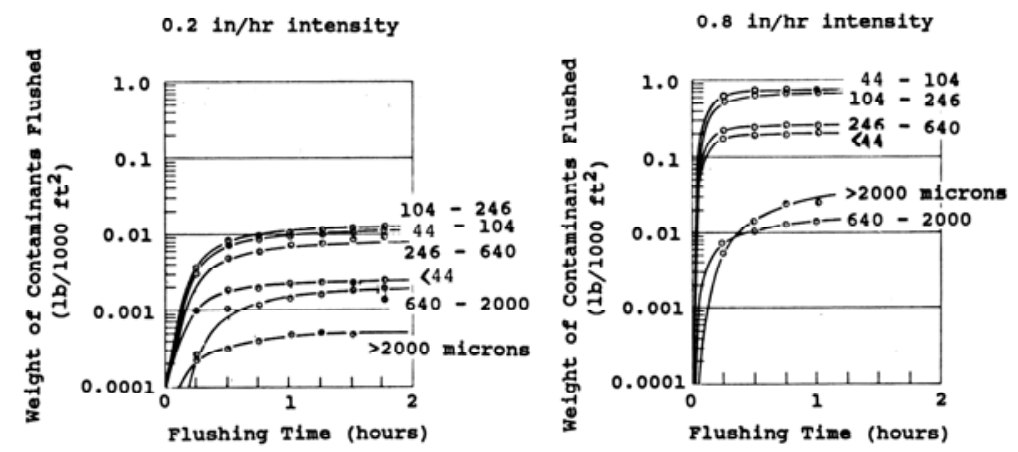

Figure 12.6 Street dirt washoff during high intensity rain tests (Sartor and Boyd 1972).

Novotny examined "before" and "after" rain event street particulate loading data using the Milwaukee NURP data (Bannerman, et al. 1983) and found almost a three-fold difference between the constant value for fine $(<45$ microns) and medium sized particles (100 to 250 microns); $0.026 / \mathrm{mm}$ for the fine particles and $0.01 / \mathrm{mm}$ for the medium sized particles, both much less than the "accepted" value. Jewell, et al. (1980) also found large variations in outfall "fitted" constant values for different rains compared to the typical default value. Either the assumption of the high removal of particulates during the $13 \mathrm{~mm} / \mathrm{h}$ storm was incorrect or/and the equation cannot be fitted to outfall data (which assumes that all the particulates are originating from homogeneous paved surfaces during all storm conditions).

This washoff equation has been used in many urban runoff models (including SWMM, STORM, and HSPF), but the No factor has been frequently misinterpreted. It has been assumed to be the total initial street loading, when in fact it is only the portion of the total street load available for washoff (the maximum asymptotic washoff load observed during the washoff tests). STORM and SWMM now use an availability factor $(A)$ for particulate 
residue as a calibration procedure in order to reduce the washoff quantity for different rain intensities (Novotny and Chesters 1981):

where

$$
A=0.057+0.04\left(r^{1.1}\right)
$$

$$
\begin{aligned}
r & =\text { the rain intensity }(\mathrm{mm} / \mathrm{h}), \text { and } \\
A & <1.0 .
\end{aligned}
$$

This regression equation is used to adjust the relative importance of the particulate residue contributions from pervious and impervious source areas. This availability factor is equal to 1.0 for all rain intensities greater than about $18 \mathrm{~mm} / \mathrm{h}$. For rains of $1 \mathrm{~mm} / \mathrm{h}$, this availability factor reduces to about 0.10 . HSPF does not use an availability factor in an attempt to be "more universally applicable" (Donigian and Crawford 1976). Instead, calibration of observed with predicted outfall yields are used to "adjust" the accumulation and washoff rates directly in HSPF. The availability factor in SWMM does not really have a significant effect on the variation of the predicted runoff load. However, it does affect the relationship between the runoff volume and the particulate washoff (and therefore concentration).

Jewell, et al. (1980) stressed the need to have local calibration data before using the exponential washoff equation, as the default values can be very misleading. The exponential washoff equation for impervious areas is justified, but washoff coefficients for each pollutant would improve its accuracy.

\subsection{Street Dirt Washoff Observations}

Particle dislodgement and transport characteristics at impervious areas can be directly measured using relatively easy washoff tests. These tests are used to supplement dry street dirt sampling at impervious source areas. Street dirt sampling, or other pavement dirt sampling, is misleading because little of the sampled street dirt actually washes off during rains.

The Bellevue, Washington, urban runoff project (Pitt 1985) included about 50 pairs of street dirt loading observations close to the beginnings and ends of rains. These before and after loading values were compared to determine significant differences in loadings that may have been caused by the rains. The observations were affected by rains falling directly on the streets, along with flows and particulates originating from non-street areas. The net loading differences were therefore affected by street dirt washoff (by direct rains on the street surfaces and by gutter flows augmented by "upstream" area runoff) 
and by erosion products that originated from non-street areas that may have settled out in the gutters. When all the data were considered together, the net loading difference was about 10 to $13 \mathrm{~g} / \mathrm{curb}-\mathrm{m}$ removed. This amounted to a street dirt load reduction of about $15 \%$, which was much less than predicted using the previously described washoff models.

Large reductions in street dirt loadings for the small particles were observed during rains in Bellevue, but the largest particles actually increased in loadings (due to settled erosion materials), as shown in Figure 12.7. The particles were not source limited, but armor shielding may have been important. Most of the weight of solid material in the runoff was concentrated in the fine particle sizes $(<63 \mu \mathrm{m})$. Very few washoff particles greater than $1,000 \mu \mathrm{m}$ were found, in fact, loadings increased for the largest sizes. Urban runoff outfall particle size analyses in Bellevue (Pitt 1985) resulted in a median particle size of about $50 \mu \mathrm{m}$. Similar results were obtained in the Milwaukee NURP study (Bannerman, et al. 1983). Many of these samples were examined by microscope to verify the source and morphology of the particulates. The particulates were all found to be discrete, with no flocculation or other binding. The runoff action was likely too violent to allow any permanent flocs to form. Binding of particulates by oils was also not observed, but could have occurred for smaller particles (a few $\mu \mathrm{m}$ in size) that could not be resolved easily in the microscope.

Particulate residue washoff predictions for Bellevue conditions were made using the Sutherland and McCuen (1978) modification of the Yalin equation, and the Sartor and Boyd (1972) equation. Three particle size groups $(<63$, 250-500, and 2000-6350 $\mu \mathrm{m}$ ), and three rains, having depths of 5, 10, and 20 $\mathrm{mm}$ and 3-hour durations, were considered. The gutter lengths for the Bellevue test areas averaged about $80 \mathrm{~m}$, with gutter slopes of about $4.5 \%$. Typical total initial street dirt loadings for the three particle sizes were: 9 $\mathrm{g} /$ curb-m for $<63 \mu \mathrm{m}, 18 \mathrm{~g} /$ curb-m for $250-500 \mu \mathrm{m}$, and $9 \mathrm{~g} /$ curb-m for 2000 $6350 \mu \mathrm{m}$. The Bellevue net loading removals during the storms was about $45 \%$ for the smallest particle size group, $17 \%$ for the middle particle size group, and $-6 \%$ (6\% loading increase) for the largest particle size group. The predicted removals were 90 to $100 \%$ using the Sutherland and McCuen method, 61 to $98 \%$ using the Sartor and Boyd equation, and 8 to $37 \%$ using the availability factor with the Sartor and Boyd equation. The ranges given reflect the different rain volumes and intensities only. There were no large predicted differences in removal percentages as a function of particle size. The availability factor with the Sartor and Boyd equation resulted in the 
closest predicted values, but the great differences in washoff as a function of particle size was not predicted.

The rain energy needed to remove larger particles is much greater than for small particles. Therefore, rains are much more effective in removing fine particles than large particles.

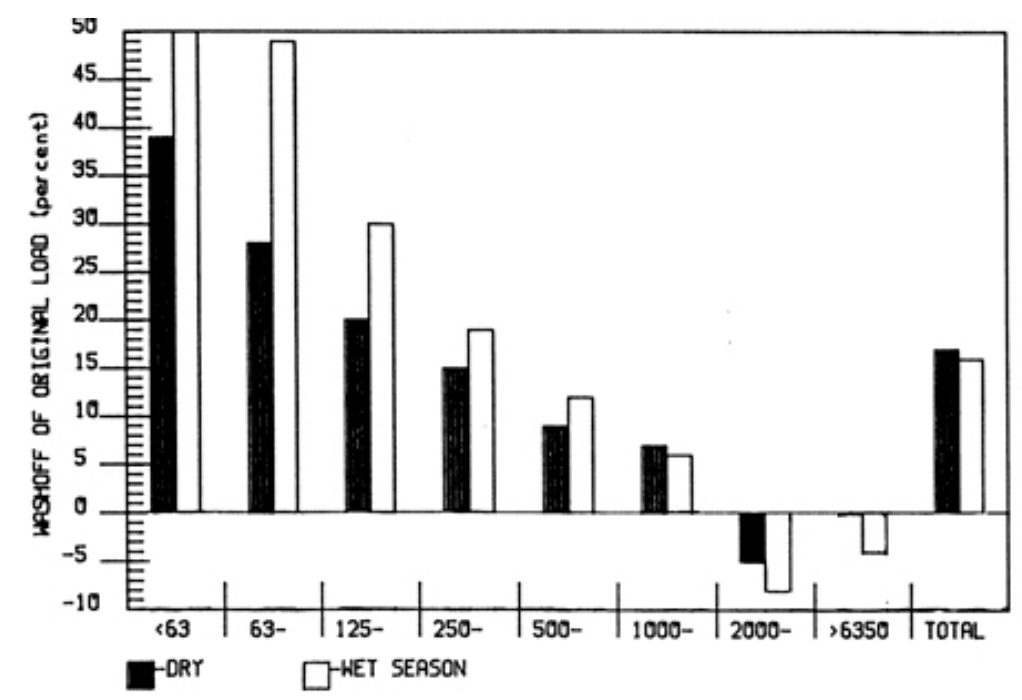

Figure 12.7 Observed washoff of street dirt during tests in Bellevue, WA (Pitt 1985).

In contrast, mechanical street cleaning equipment preferentially removes the larger particles compared to the small particles. Vacuum street cleaning equipment should be able to remove the finer particles better than the larger particles, but most vacuum street cleaners cannot remove the fine particles effectively under typically moist conditions and in the presence of larger particles that cover most of the finer street dirt. Therefore, particles of different sizes "behave" quite differently on streets. Typical street dirt total solids loadings show a "saw-tooth" pattern with time between street cleaning or rain washoff events. The patterns for the separate particle sizes are considerably different than the pattern for total residue. Typical mechanical street cleaners remove much (about 70\%) of the coarse particles in the path of the street cleaner, but they remove very little of the finer particles (Sartor and Boyd 1972; Pitt 1979). Rains, however, remove very little of the large particles, but can remove large amounts (about 50\%) of the fine particles 
(Bannerman, et al. 1983; Pitt 1985; Pitt 1987). The intermediate particle sizes show reduced removals by both street cleaners and rain.

The Bellevue street dirt washoff observations included effects of additional runoff volume and particulates originating from non-street areas. The additional flows should have produced more gutter particulate washoff, but upland erosion materials may also have settled in the gutters (as noted for the large particles). However, across-the-street dirt loading measurements indicated that much of the street dirt was in the street lanes, not in the gutters, before and after rains. This dirt distribution reduces the importance of these extra flows and particulates from upland areas. The increased loadings of the largest particles after rains were obviously caused by upland erosion, but the magnitude of the settled amounts was quite small compared to the total street dirt loadings.

\subsubsection{Small-Scale Washoff Tests}

Street dirt has a wide range of particle sizes and the chemical quality varied greatly for the different particle sizes. It is therefore important to mostly focus on the fraction that will be removed during rains. There is much confusion (and error) if the easily measured street dirt loadings are assumed to be totally available for washoff. Washoff tests can therefore be used to estimate the fraction of the total loading measured on the street that can be removed during rains.

In order to clarify street dirt washoff, Pitt (1987) conducted numerous controlled washoff tests on city streets in Toronto. These tests were arranged as an overlapping series of 23 factorial tests, and were analyzed using standard factorial test procedures described by Box, et al. (1978). The experimental factors examined included: rain intensity, street texture, and street dirt loading. The differences between available and total street dirt loads were also related to the experimental factors. The samples were analyzed for total solids (total residue), dissolved solids (filterable residue: $<0.45 \mu \mathrm{m}$ ), and SS (particulate residue: $>0.45 \mu \mathrm{m}$ ). Runoff samples were also filtered through $0.45 \mu \mathrm{m}$ filters and the captured material on the filters was microscopically analyzed (using low power polarized light microscopes to differentiate between inorganic and organic debris) to determine particulate size distributions from about 1 to $500 \mu \mathrm{m}$. The runoff flow quantities were also carefully monitored to determine the magnitude of initial and total rain water losses on impervious surfaces. 
Table 12.2 presents the site data along with the basic rain and runoff observations obtained during these tests. All tests were conducted for about two hours, with total rain volumes ranging from about 5 to $25 \mathrm{~mm}$. The test code explanations are shown in Table 12.3. Table 12.2 shows the specific experimental levels that each variable was held to during each test. Unfortunately, the streets during the LDS test were not as dirty as anticipated and the test was actually a replicate with the LCS tests. The statistical analyses were modified to indicate these unanticipated duplicate observations.

A simple artificial rain simulator was constructed using 12 lengths of "soaker" hose, suspended on a wooden framework about one $\mathrm{m}$ above the road surface (Figure 12.8). This test setup was designed and tested to best represent actual rainfall conditions. Pitt (1987) describes rain energy and drop size in natural events.

Table 12.2 Experimental Levels for each Test Factor

\begin{tabular}{|c|c|c|c|}
\hline & Rain intensity & Street dirt loading & Street texture \\
\hline $\begin{array}{l}\text { Expected to enhance } \\
\text { percentage washoff: }\end{array}$ & $\begin{array}{l}\text { High }(11.0 \text { to } \\
12.2 \mathrm{~mm} / \mathrm{h})\end{array}$ & $\begin{array}{l}\text { Dirty }(10.5 \text { to } 12.6 \\
\left.\mathrm{g} / \mathrm{m}^{2}\right)\end{array}$ & $\begin{array}{l}\text { Smooth ( } 0.3 \text { to } 0.4 \mathrm{~mm} \\
\text { detention storage) }\end{array}$ \\
\hline $\begin{array}{l}\text { Expected to retard } \\
\text { percentage washoff: }\end{array}$ & $\begin{array}{l}\text { Low }(2.9 \text { to } \\
3.2 \mathrm{~mm} / \mathrm{h})\end{array}$ & $\begin{array}{l}\text { Clean (1.7 to } 2.6 \\
\left.\mathrm{~g} / \mathrm{m}^{2}\right)\end{array}$ & $\begin{array}{l}\text { Rough (1.1 mm detention } \\
\text { storage) }\end{array}$ \\
\hline
\end{tabular}

Table 12.3 Test Codes for Washoff Tests

\begin{tabular}{llll}
\hline Test code & Rain intensity & $\begin{array}{l}\text { Street dirt } \\
\text { loading }\end{array}$ & Street texture \\
\hline HCR & High & Clean & Rough \\
HDR & High & Dirty & Rough \\
LCR & Light & Clean & Rough \\
LDR & Light & Dirty & Rough \\
HCS & High & Clean & Smooth \\
HDS & High & Dirty & Smooth \\
LCS & Light & Clean & Smooth \\
\hline LDS $($ LCS $)$ & Light & Dirty & Smooth \\
\hline
\end{tabular}

Toronto rain conditions were examined and representative "rain" intensities were used during these tests to represent average rain intensities $(3 \mathrm{~mm} / \mathrm{h})$ and peak rain intensities $(12 \mathrm{~mm} / \mathrm{h})$. Commonly used $50 \mathrm{~mm} / \mathrm{h}$ rain intensities used in agricultural runoff and infiltration studies would only be applicable for the most extreme and short rain periods. A number of alternative setups were tested indoors in a large Toronto public works warehouse. This setup was the most practicable when using these relatively "small" intensities 
(compared to the agricultural tests, or the Rain Bird sprinkler setups used by Sartor and Boyd, 1972, during their washoff tests). Drop sizes were estimated using flour pans that were uncovered for short periods so the "rain" drop sizes could be indicated by holes in the deep flour. The kinetic energies of the "rains" during these tests were therefore comparable to actual rains under investigation.

"Rain" was applied by connecting the hoses to a manifold, having individual valves to adjust constant rain intensities for the different areas. The manifold was in turn connected to a fire hydrant. The flow rate needed for each test was calculated based on the desired rain intensity and the area covered. The flow rates were carefully monitored by using a series of ball flow gauges before the manifold. The distributions of the test rains over the study areas were also monitored by placing about 20 small beakers over the area during the rains. In order to keep the drop sizes representative of sizes found during natural rains, the surface tension of the water drops hanging on the plastic soaker hoses was reduced by applying a light coating of Teflon ${ }^{\circledR}$ spray to the hoses.

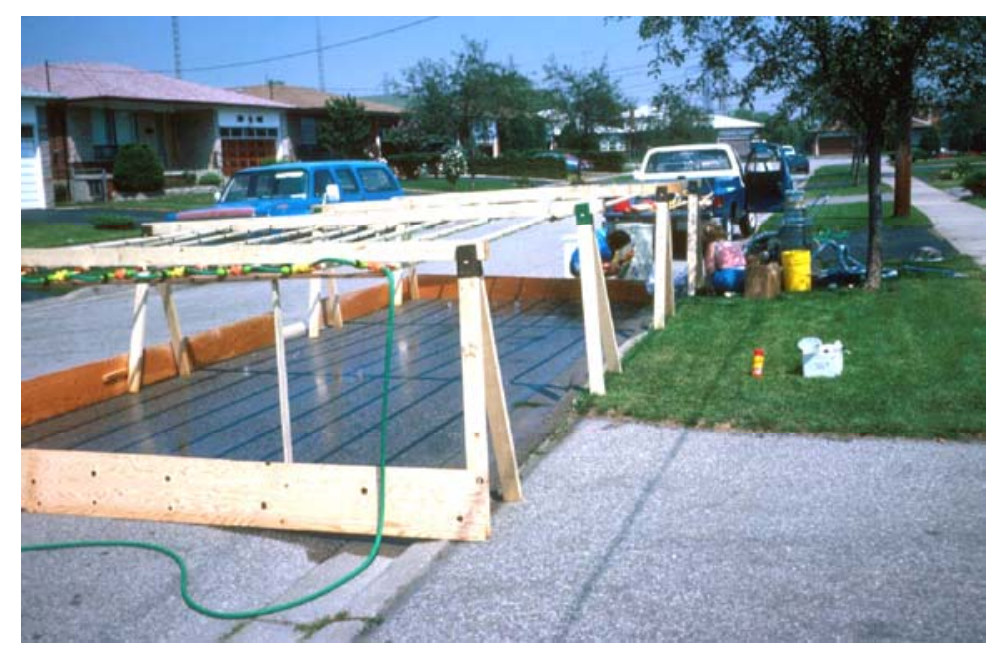

Figure 12.8 Small-scale washoff test setup in Toronto (Pitt 1987).

It was difficult to obtain even distributions of rain during the light rain tests in Toronto using the manifold, so a single hose was used that was manually moved back and forth over the test area during the smaller rain tests (three people took 30-minute shifts). To keep evaporation reasonable for the rain 
conditions, the test sites were also shaded during sunny test days. Blank water samples were also obtained from the manifold for background residue analyses; otherwise, the filterable residue of the "rain" water (about 185 $\mathrm{mg} / \mathrm{L}$ ) could cause substantial errors when calculating total solids washoff.

The areas studied were about 3 by $7 \mathrm{~ms}$ each. The street side edges of the test areas were edged with plywood, about $30 \mathrm{~cm}$ in height and imbedded in thick caulking, to direct the runoff towards the curbs with minimal leakage. All runoff was pumped continuously from downstream sumps (made of caulking and plastic sand bags) to graduated $1000 \mathrm{~L}$ Nalgene containers. The washoff samples were obtained from the pumped water going to the containers every 5 to 10 minutes at the beginning of the tests, and every 30 minutes near the end of the test. Final complete rinses of the test areas were also conducted (and sampled) at the tests' conclusions to determine total loadings of the monitored constituents.

The samples were analyzed for total residue, filtrate residue (TDS), and particulate residue (SS), along with bacteria. Runoff samples were also filtered through 0.4 micron filters and microscopically analyzed (using polarized light microscopes to differentiate between inorganic and organic debris) to determine particulate residue size distributions from about 1 to 500 microns. The runoff flow quantities were also carefully monitored to determine the magnitude of initial and total rain water losses on impervious surfaces.

These tests were different from the important earlier Sartor and Boyd (1972) washoff experiments in the following ways:

- They were organized in overlapping factorial experimental designs to identify the most important main factors and interactions.

- Particle sizes were measured down to about one micron (in addition to particulate residue and filterable residue measurements).

- The precipitation intensities were lower in order to better represent actual rain conditions of the upper Midwest.

- Observations were made with more resolution at the beginning of the tests.

- Washoff flow rates were frequently measured.

- Emphasis was placed on total street loading, not just total available loading.

- Bacteria population measurements were also periodically obtained. 
Figure 12.9 is a plot of suspended solids concentrations during these tests. The suspended solids concentrations varied from about 2 to $1500 \mathrm{mg} / \mathrm{L}$, with an obvious decrease in concentrations with increasing rain depths during these constant rain intensity tests. No concentrations greater than $500 \mathrm{mg} / \mathrm{L}$ occurred after about two $\mathrm{mm}$ of rain. All concentrations after about $10 \mathrm{~mm}$ of rain were less than $100 \mathrm{mg} / \mathrm{L}$. The dissolved solids $(<0.45 \mu \mathrm{m})$ concentrations ranged from about 20 to $900 \mathrm{mg} / \mathrm{L}$, comprising a surprisingly large percentage of the total solids loadings. For small rain depths, dissolved solids comprised up to $90 \%$ of the total solids. After $10 \mathrm{~mm}$ of rain depth, the filterable residue concentrations were all less than about $50 \mathrm{mg} / \mathrm{L}$ (increased compared to background concentrations in the test water).

Manual particle size analyses were also conducted on the suspended solids washoff samples, using a microscope with a calibrated recticule.

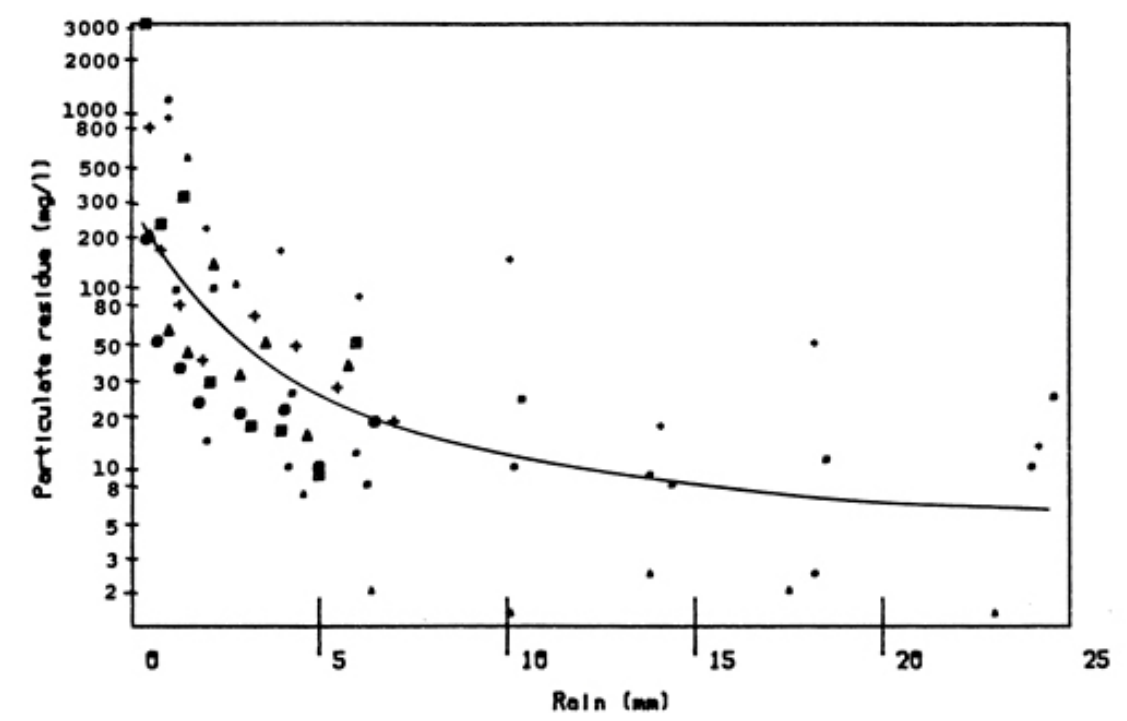

Figure 12.9 Suspended solids concentration decreases with rain depth increases during constant rain intensity washoff tests in Toronto (Pitt 1987).

Figure 12.10 is a photo of an updated setup using a computer-assisted particle measuring program. The tests shown here were evaluated in the early $1980 \mathrm{~s}$ before such computer-assisted procedures were commonly available. The same microscope was used for the tests shown here, a research-grade Olympus microscope using polarized light. The samples were filtered onto 
standard $0.45 \mu \mathrm{m}$ pore size membrane filters soon after sample collection (within 2 days to prevent degradation of the sample integrity due to biological growths and to minimize possible flocculation). Scanning of the filter was used to identify a microscopic field that had minimal particle overlapping (initial trials were also conducted to determine the amount of sample to filter to minimize overlapping). Microscopic examinations were primarily used to identify the type and morphology of the particles, using the McCrone Associates' Particle Atlas (Chicago, IL) (McCrone, et al. 1967). This enabled the identification of the original origin of the particles (mostly erosion product local minerals, tire wear rubber, road asphalt, and vegetative matter). Microscopic examinations also confirmed that the washoff particles were discrete and not flocculated, or bound together by oils.

Figure 12.11 is an example microphotograph of a washoff sample. The largest particle in this field is about $100 \mu \mathrm{m}$ long. The smallest particles that could be manually measured were about $1 \mu \mathrm{m}$. A full discussion of the methods that can be used to measure stormwater particles is beyond the scope of this chapter.

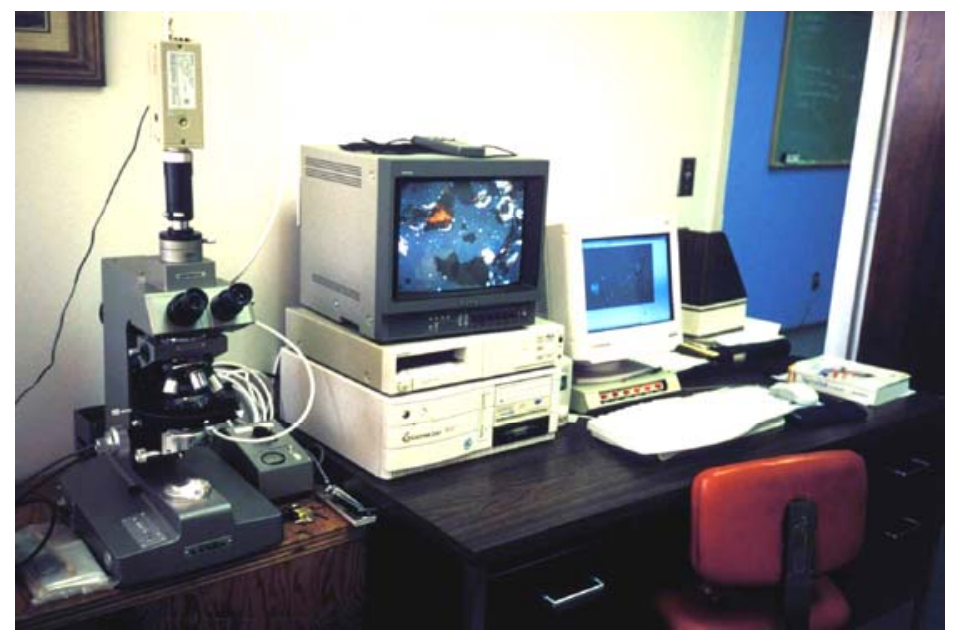

Figure 12.10 Light microscope and video capture that can be used to measure particle sizes from washoff experiments.

Currently, our lab relies on Coulter Counter methods (after cone splitting of samples and pre-sieving). Small-scale Teflon settling column tests have also been used to verify the microscopic and Coulter Counter test methods. However, microscopic examinations of samples can greatly add to our 
understanding of stormwater processes and is generally available to researchers. Burton and Pitt (2002) contains some additional information on these methods, especially the care that needs to be taken when collecting samples to best represent particle size.

Figure 12.12 is an example of particle size distributions for a test. This plot shows the percentage of the particles that were less than various sizes, by measured particle volume (assumed to be similar to weight). The plot also indicates median particle sizes of about 15 to $50 \mu \mathrm{m}$, depending on when the sample was obtained during the washoff tests. All of the distributions for all of the tests showed surprisingly similar trends of particle sizes with elapsed rain depth. The median size for the sample obtained at about one $\mathrm{mm}$ of rain was much greater than for the samples taken after more rain, likely associated with large, but light-weight vegetative matter. The median particle sizes of material remaining on the streets after the washoff tests were also much larger than for most of the runoff samples, but were quite close to the initial samples' median particle sizes.

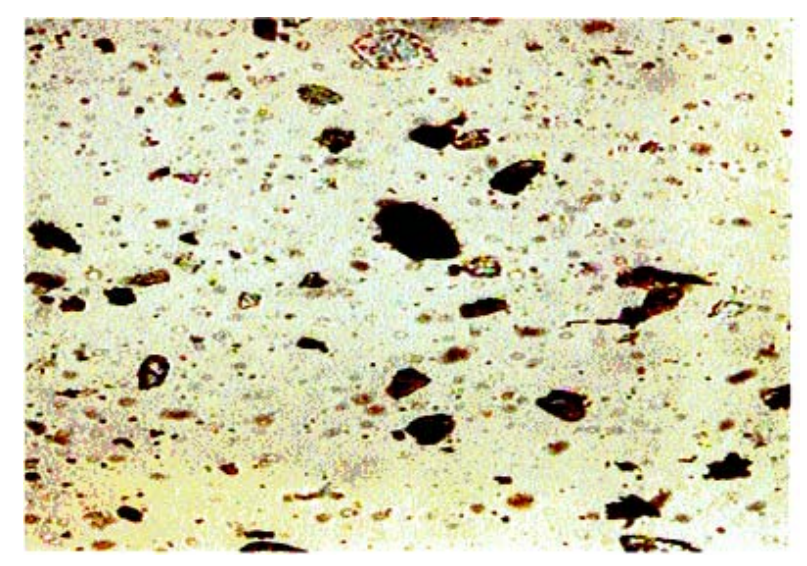

Figure 12.11 Example photomicrograph of street washoff test sample.

Most street runoff waters during test rains in the 5 to $15 \mathrm{~mm}$ depth category had median suspended solids particle sizes of about 10 to $50 \mu \mathrm{m}$. However, dissolved solids (less than $0.45 \mu \mathrm{m}$ ) made up most of the total solids washoff for elapsed rain depths greater than about five $\mathrm{mm}$. The large particles during the initial runoff periods were mostly relatively light (and large) vegetative matter (degraded leaves and grass clippings) that were much easier to remove compared to the heavier "soil" matter. In addition, the initial rain impacts on 
the dry streets likely resulted in more "splash" related energy, compared to later periods when there was a thin film of flowing water moving across the asphalt surface that could dislodge disproportionately larger material. Finally, relatively long "soaking" periods were found to be necessary to soften compacted and cohesive finer street dirt material. None of the sediments were found to be source-limited, as substantial amounts remained on the streets after the "rains." However, much more of the total amount of finer material was washed from the streets than the coarser material.

These particle size distributions indicate that the smaller particles were much more important than indicated during previous tests. As an example, the Sartor and Boyd (1972) washoff tests (rain intensities of $50 \mathrm{~mm} / \mathrm{h}$ for two hour durations) found median particle sizes of about $150 \mu \mathrm{m}$ which were typically three to five times larger than were found during these lowerintensity tests. They also did not find any significant particle size distribution differences for different rain depths (or rain duration), in contrast to the Toronto tests, which were conducted at more common rain intensities ( 3 to 12 $\mathrm{mm} / \mathrm{h}$ for two hours).

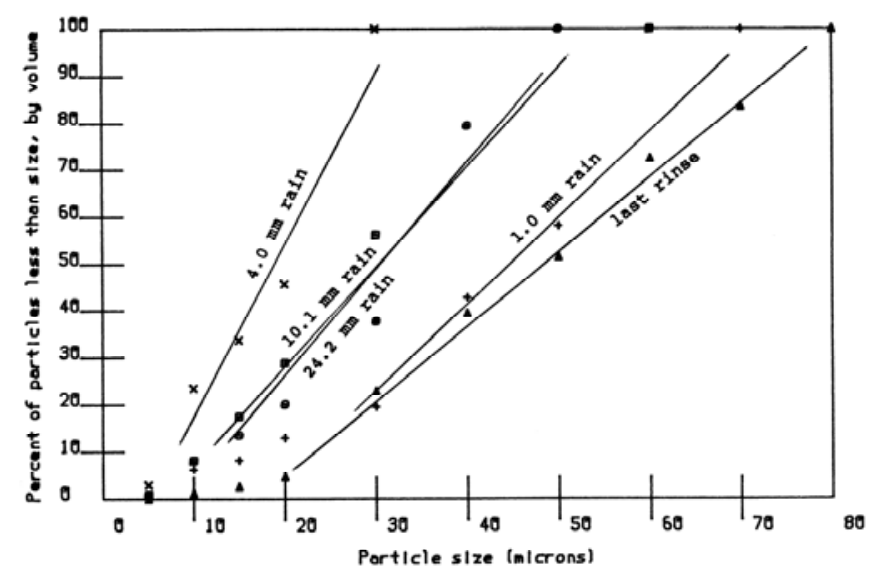

Figure 12.12 Particle size distributions during high rain intensity, dirty, and smooth street (HDS), tests (Pitt 1987).

\subsection{Washoff Equations for Individual Tests}

The particulate washoff values obtained during these Toronto tests were expressed in units of grams per square meter and grams per curb-meter, concentrations $(\mathrm{mg} / \mathrm{L})$, and the percent of the total initial loading washed off 
during the test. Prior publications in this book series (Pitt 1997) have shown all the data plots for these tests. Therefore, only Figure 12.13 is presented here as an example. These plots show the asymptotic washoff values observed in the tests, along with the measured total street dirt loadings. The maximum asymptotic values are the "available" street dirt loadings (No). The measured total loadings are seen to be several times larger than these "available" loading values. As an example, the asymptotic available total solids value for the HDS (high intensity rain, dirty street, smooth street) test was about $3 \mathrm{~g} / \mathrm{m}^{2}$ while the total load on the street for this test was about $14 \mathrm{~g} / \mathrm{m}^{2}$, or about five times the available load. The differences between available and total loadings for the other tests were even greater, with the total loads typically about ten times greater than the available loads. The total loading and available loading values for dissolved solids were quite close, indicating almost complete washoff of the very small particles. However, the differences between the two loading values for SS were much greater. Shielding, therefore, may not have been very important during these tests, as almost all of the smallest particles were removed, even in the presence of heavy loadings of large particles.

The actual data are shown on these figures, along with the fitted Sartor and Boyd exponential washoff equations. In many cases, the fitted washoff equations greatly over-predicted suspended solids washoff during the very small rains (usually less than one to three $\mathrm{mm}$ in depth), possibly due to shielding. In all cases, the fitted washoff equations described suspended solids washoff very well for rains greater than about $10 \mathrm{~mm}$ in depth.

Tables 12.4 through 12.6 present the equation parameters for each of the eight washoff tests for total solids, suspended solids, and filterable solids. Pitt (1987) concluded that particulate washoff (defined by the suspended solids washoff) should be divided into two main categories, one for high intensity rains with dirty streets, possibly divided into categories by street texture, and the other for all other conditions. Factorial tests also found that the availability factor (the ratio of the available loading, $N_{0}$, to the total loading) varied depending on the rain intensity and the street roughness, as indicated below:

- low rain intensity and rough streets: 0.045

- high rain intensity and rough streets, or low rain intensity and smooth streets: 0.075

- high rain intensity and smooth streets: 0.20

Obviously, washoff was more efficient for the higher rain energy and smoother pavement tests. The worst case was for a low rain intensity and rough street, where only about $4.5 \%$ of the street dirt would be washed from 
the pavement. In contrast, the high rain intensities on the smooth streets were more than four times more efficient in removing the street dirt.

If a selected model requires available loading values instead of the total loading values, then a procedure must be used to adjust the total loading values (such as attempted by the availability term in STORM and SWMM). In all cases, the $k$ term must be appropriate for the model form. However, the use of an available loading value for $N_{o}$ requires the use of a substantially larger $\mathrm{k}$ term compared to using the total loading value.

Selecting the appropriate $\mathrm{k}$ term for the correct form of No is critical. As an example, the rain volume needed to produce $90 \%$ washoff can be calculated using the standard washoff equation as follows:

$$
N=N_{o} e^{-k R}
$$

for $90 \%$ washoff, $N=0.1 N_{o}$, and $0.1 N_{o}=N_{o} e^{-k R}$, or $0.1=e^{-k R}$, and

$(1 / k) \log e(0.1)=R$, therefore $R=2.303 / k$ for $90 \%$ washoff.
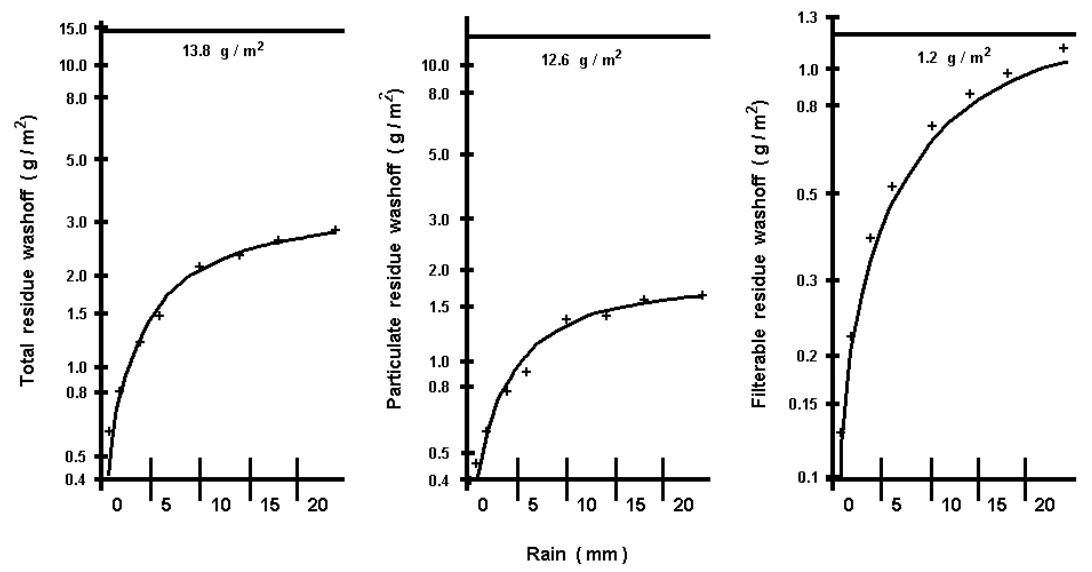

Figure 12.13 Washoff plots for HDS test (high rain intensity, dirty, and smooth street) (Pitt 1987). 
Table 12.14 Total solids washoff coefficients (Pitt 1987)1

\begin{tabular}{llllllllll}
\hline $\begin{array}{l}\text { Test } \\
\text { code }\end{array}$ & Rain & 1 & 2 & 3 & $\mathrm{k}$ & 4 & 5 & $\mathrm{k}$ & 4 \\
\hline HCR & high & clean & $\mathrm{r}$ & 3.25 & 0.016 & 0.002 & 0.84 & 0.145 & 0.018 \\
LCR & low & clean & $\mathrm{r}$ & 2.99 & 0.038 & 0.001 & 0.58 & 0.304 & 0.032 \\
HDR & high & dirty & $\mathrm{r}$ & 12.82 & 0.004 & $<0.001$ & 1.14 & 0.078 & 0.006 \\
LDR & low & dirty & $\mathrm{r}$ & 11.22 & 0.013 & 0.001 & 0.74 & 0.383 & 0.024 \\
HCS & high & clean & $\mathrm{s}$ & 2.62 & 0.033 & 0.005 & 1.21 & 0.146 & 0.021 \\
LCS & low & clean & $\mathrm{s}$ & 2.32 & 0.026 & 0.001 & 0.35 & 0.301 & 0.024 \\
HDS & high & dirty & $\mathrm{s}$ & 13.82 & 0.012 & 0.001 & 2.74 & 0.138 & 0.008 \\
\hline LCS & low & clean & $\mathrm{s}$ & 2.42 & 0.042 & 0.002 & 0.57 & 0.300 & 0.024 \\
\hline
\end{tabular}

Notes:

1. Street dirt loading;

2. Street texture; $r=$ rough, $s=$ smooth

3. $N_{o}\left(\mathrm{~g} / \mathrm{m}^{2}\right)$ measured total initial total solids load;

4. Standard error for $k(1 / \mathrm{hr})$;

5. $N_{o}\left(\mathrm{~g} / \mathrm{m}^{2}\right)$ available initial total solids load $N=N_{o} e^{-k R}$ 
Table 12.15 Suspended solids washoff coefficients (Pitt 1987).

\begin{tabular}{llllllll}
\hline $\begin{array}{l}\text { Test } \\
\text { code }\end{array}$ & Rain & $\begin{array}{l}\text { Street } \\
\text { dirt } \\
\text { loading }\end{array}$ & $\begin{array}{l}\text { Street } \\
\text { texture }\end{array}$ & $\begin{array}{l}N_{o} \\
\left(\mathrm{~g} / \mathrm{m}^{2}\right) \\
\text { available } \\
\text { suspended } \\
\text { solids load }\end{array}$ & $\begin{array}{l}k \\
(1 / \mathrm{hr})\end{array}$ & $\begin{array}{l}\text { Standard } \\
\text { error for k } \\
(1 / \mathrm{hr})\end{array}$ & $\begin{array}{l}\text { Ratio of } \\
\text { available } \\
\text { load to total } \\
\text { initial load }\end{array}$ \\
\hline HCR & high & clean & rough & 0.295 & 0.832 & 0.064 & 0.11 \\
LCR & low & clean & rough & 0.138 & 0.344 & 0.038 & 0.061 \\
HDR & high & dirty & rough & 0.375 & 0.077 & 0.008 & 0.032 \\
LDR & low & dirty & rough & 0.291 & 0.619 & 0.052 & 0.028 \\
HCS & high & clean & smooth & 0.462 & 1.007 & 0.321 & 0.26 \\
LCS & low & clean & smooth & 0.091 & 0.302 & 0.024 & 0.047 \\
HDS & high & dirty & smooth & 1.66 & 0.167 & 0.015 & 0.13 \\
\hline LCS & low & clean & smooth & 0.209 & 0.335 & 0.031 & 0.11 \\
\hline
\end{tabular}

Table 12.16 Filterable solids washoff coefficients (Pitt 1987).

\begin{tabular}{lllllll}
\hline $\begin{array}{l}\text { Test } \\
\text { code }\end{array}$ & $\begin{array}{l}\text { Rain } \\
\text { intensity }\end{array}$ & $\begin{array}{l}\text { Street dirt } \\
\text { loading }\end{array}$ & $\begin{array}{l}\text { Street } \\
\text { texture }\end{array}$ & $\begin{array}{l}\mathrm{N}_{\mathrm{o}} \\
\left(\mathrm{g} / \mathrm{m}^{2}\right) \text { measured } \\
\text { total initial } \\
\text { filterable solids load }\end{array}$ & $\begin{array}{l}\mathrm{k} \\
(1 / \mathrm{hr})\end{array}$ & $\begin{array}{l}\text { Standard error } \\
\text { for } \mathrm{k} \\
(1 / \mathrm{hr})\end{array}$ \\
\hline HCR & high & clean & rough & 0.651 & 0.061 & 0.004 \\
LCR & low & clean & rough & 0.745 & 0.139 & 0.006 \\
HDR & high & dirty & rough & 0.915 & 0.058 & 0.002 \\
LDR & low & dirty & rough & 0.680 & 0.163 & 0.006 \\
HCS & high & clean & smooth & 0.871 & 0.070 & 0.003 \\
LCS & low & clean & smooth & 0.395 & 0.154 & 0.007 \\
HDS & high & dirty & smooth & 1.223 & 0.085 & 0.002 \\
\hline LCS & low & clean & smooth & 0.463 & 0.183 & 0.008 \\
\hline
\end{tabular}


Values for $k$ and rain quantities $(\mathrm{mm})$ to produce specific \% washoffs are:

\begin{tabular}{ll}
\hline$\%$ washoff & Rain needed $(\mathrm{mm}):$ \\
\hline 99.9 & $6.908 / \mathrm{k}$ \\
99 & $4.605 / \mathrm{k}$ \\
95 & $2.996 / \mathrm{k}$ \\
90 & $2.303 / \mathrm{k}$ \\
75 & $1.386 / \mathrm{k}$ \\
50 & $0.693 / \mathrm{k}$ \\
25 & $0.288 / \mathrm{k}$ \\
\hline 10 & $0.105 / \mathrm{k}$ \\
\hline
\end{tabular}

It is obvious that washoff occurs faster for larger $\mathrm{k}$ values (the washoff curves presented in Figure 12.13 would be steeper for larger $\mathrm{k}$ values if the figures were plotted without log scales).

Table 12.7 contains the availability relationship for suspended solids. "I" is the rain intensity; the high value is related to the $12 \mathrm{~mm} / \mathrm{h}$ test conditions, while the low value is related to the $3 \mathrm{~mm} / \mathrm{h}$ test conditions. The " $\mathrm{T}$ " factor is the street surface texture, corresponding to rough and smooth surfaced streets. The street textures were directly related to detention storage through plaster casts and rubber replicates (rough: $1.1 \mathrm{~mm}$; smooth: about $0.35 \mathrm{~mm}$ detention storage). A carpenter's wire "feeler" gauge was also used to profile the street textures. The street dirt loading factor was not significant in predicting the availability factor. These methods and results are described in Pitt (1987).

Table 12.7 Fraction of total street dirt suspended solids available for washoff (Pitt 1987).

Ratio of "available" particulate residue (SS) loadings to total particulate residue loadings:

$$
\begin{gathered}
\mathrm{I}=0.08 \pm 0.04 \\
\mathrm{~T}=-0.08 \pm 0.05 \\
\hat{\mathrm{Y}}=0.097+0.04(\mathrm{I})-0.04(\mathrm{~T})
\end{gathered}
$$

I+T + (high and rough): $\quad \hat{\mathrm{Y}}=0.10$

I+T- (high and smooth): $\quad \hat{Y}=0.18$

I-T+ (low and rough): $\quad \hat{Y}=0.02$

I-T- (low and smooth): $\quad \hat{Y}=0.10$ 


\subsection{Maximum Washoff Capacity}

Another important consideration in calculating washoff of street dirt during rains is the carrying capacity of the flowing water. If the shear stress of the flowing water is high, it is much more capable of carrying particulates than for lower shear stresses. There is a physical limit to the ability of water to transport sediment. In contrast, the conventional washoff plots and equations presented earlier result in a "percentage" washoff of the total load, irrespective of the resultant concentration. However, when observing the plot of suspended solids concentration vs. rain depth for many washoff test plots (Figure 12.14), the pattern is quite distinct and appears to be generally independent on initial street loading (there is substantial scatter in this plot which likely reflects some site conditions). The washoff mostly is controlled by the carrying capacity of the water, and not source limitations, as there is substantial material on the street after the end of most rains. Therefore, this carrying capacity must be considered when predicting washoff quantities. If the calculated washoff is greater than the carrying capacity (such as would occur for relatively heavy street dirt loads and low to moderate rain intensities), then the carrying capacity is limiting. For high rain intensities, the carrying capacity is likely sufficient to transport most all of the washoff material.

In order to determine this carrying capacity for street runoff, data from the washoff tests conducted by Pitt (1987) and Sartor and Boyd (1972) were further examined. The maximum washoff amounts $\left(\mathrm{g} / \mathrm{m}^{2}\right)$ for the different tests conducted on smooth streets were plotted against the rain intensity $(\mathrm{mm} / \mathrm{h})$ used for the tests. This plot is shown in Figure 12.14, illustrating the exponential equation fitted to these data:

where:

$$
W=0.0636 e^{0.237 P}
$$

$$
\begin{aligned}
W & =\text { the maximum washoff, } \mathrm{g} / \mathrm{m}^{2}, \text { and } \\
P & =\text { average rain intensity, } \mathrm{mm} / \mathrm{h}
\end{aligned}
$$

These are the maximum washoff values possible, representing the carrying capacity of the runoff. If the predicted washoff, using the previous "standard" washoff equations, is smaller than the values shown in this figure, then those values can be used directly. However, if the predicted washoff is greater than the values shown in this figure, then the values in the figure should be used. It is expected that washoff limitations for rough streets would be more restrictive, but insufficient data were available to develop a similar plot. 
The resulting sheetflow concentrations associated with these maximum washoff values depends on the rain durations at these average rain intensities. As an example, for typical $6 \mathrm{~h}$ rain durations, the resulting concentrations are very similar to the fitted line on the suspended solids concentration vs. rain depth plot shown on Figure 12.9 (about $100 \mathrm{mg} / \mathrm{L}$ for 1 to $2 \mathrm{~mm}$ rains, decreasing to about $10 \mathrm{mg} / \mathrm{L}$ for rains of about $25 \mathrm{~mm}$ in depth). For very large rains, having sustained high rain intensities, the available street dirt loading would most likely be limiting.

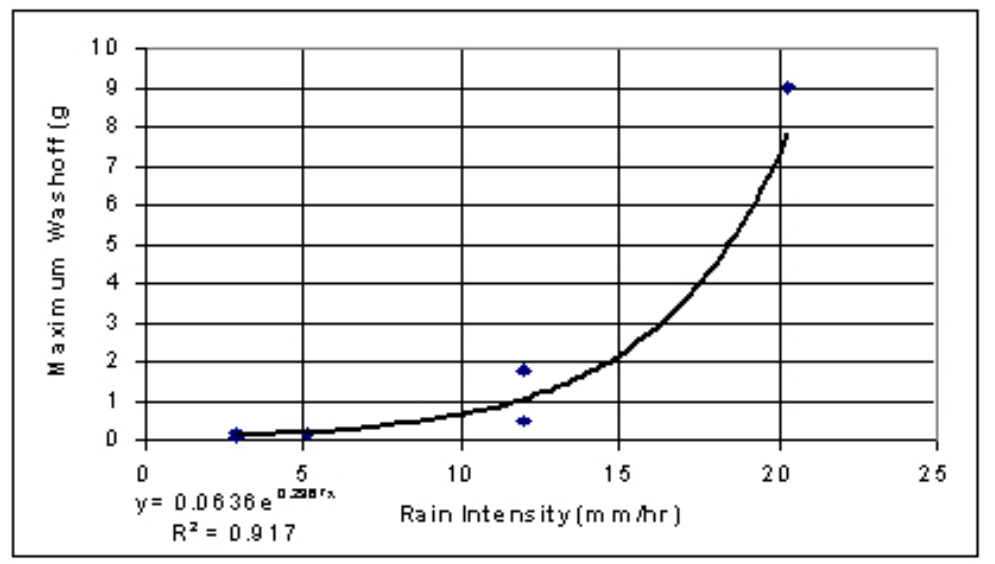

Figure 12.14 Maximum washoff capacity for smooth streets (based on Pitt 1987 and Sartor and Boyd 1972 measurements).

\subsection{Comparison of Particulate Residue Washoff Using Washoff Models}

This discussion briefly compares the washoff observations obtained during these washoff tests with predicted washoff values obtained using the Sartor and Boyd (1972) washoff model (with and without the "availability" factor). Table 12.8 shows the predicted washoff values along with the observed values for the conditions that occurred during the washoff tests. In all cases, serious over-predictions in street dirt washoff resulted by using these common washoff models. Even with the availability factor, the predicted Sartor and Boyd washoff quantities were almost two to more than five times greater than 
observed. Without the availability factor, the modeled washoff quantities were at least five times greater than the observed values. The residuals (all reflecting over-predictions) of these modeled estimates ranged from 0.2 to 7 $\mathrm{g} / \mathrm{m}^{2}$ when using the availability factor, compared to residuals mostly less than $0.05 \mathrm{~g} / \mathrm{m}^{2}$ when the model developed from these washoff tests was used. Lower residuals obtained by using the revised model could be expected because these data were not independent from the data used in developing the revised washoff model.

Table 12.8 Comparisons of Observed Washoff Test Results with Sartor and Boyd Equation Predictions (Pitt 1987).

\begin{tabular}{clll}
\hline & $\begin{array}{l}\text { Calculated Sartor } \\
\text { and Boyd washoff } \\
\left(\mathrm{g} / \mathrm{m}^{2}\right)\end{array}$ & $\begin{array}{l}\text { Calculated Sartor and Boyd } \\
\text { washoff, with availability } \\
\text { factor }\left(\mathrm{g} / \mathrm{m}^{2}\right)\end{array}$ & $\begin{array}{l}\text { Observed } \\
\text { washoff } \\
\left(\mathrm{g} / \mathrm{m}^{2}\right)\end{array}$ \\
\hline $\begin{array}{c}\text { Clean Streets } \\
\text { Light rains }\end{array}$ & 1.47 & 0.28 & 0.08 to 0.18 \\
$\begin{array}{c}\text { Heavy rains } \\
\text { Dirty Streets } \\
\text { Light rains }\end{array}$ & 2.17 & 1.41 & 0.28 to 0.45 \\
\hline Heavy rains & 7.73 & 1.47 & 0.28 \\
\hline
\end{tabular}

As stated previously, over-predicted street dirt washoff quantities would result in under-predictions of particulate residue from other sources during model calibration. These over-predictions, especially combined with commonly over-predicted runoff flow volumes, dramatically affect the relative importance of different urban runoff pollutant source areas and estimated effectiveness of source area controls.

\subsection{Conclusions}

This Chapter summarized street particulate washoff observations obtained during special washoff tests, along with associated street dirt accumulation measurements. The objectives of these tests were to identify the significant rain and street factors affecting particulate washoff and to develop appropriate washoff models. These tests and calculations were also used to clarify apparent confusion caused by misuse of washoff equations in urban runoff models. 
The controlled washoff experiments identified important relationships between "available" and "total" particulate loadings and the significant effects of the test variables on the washoff model parameters. Past modeling efforts have typically ignored or misused this relationship to inaccurately predict the importance of street particulate washoff. The available loadings were almost completely washed off streets during rains of about $25 \mathrm{~mm}$ (as previously assumed). However, the fraction of the total loading that was available was at most only $20 \%$ of the total loading, and averaged only $10 \%$, with resultant actual washoffs of only about $9 \%$ of the total loadings. Based on extrapolating the washoff models, only very large rains (possibly approaching $100 \mathrm{~mm}$ in depth) could ever be expected to wash off most of the total particulate street dirt load. These very large rains are well beyond the range of any washoff tests, but they do periodically occur in some parts of the world. However, observed street dirt washoff during actual rains near this size have not produced substantially greater washoff quantities than observed during the tests conducted during this research. The correctly used exponential washoff models only appear to be applicable for rains in the range of about 3 to 30 $\mathrm{mm}$, which are the most important rains for water quality studies in most areas.

The fractions of the particulate residue (SS) loadings available for washoff were affected by both rain intensity and texture. In many model applications, total initial loading values (as usually measured during field studies) are used in conjunction with model parameters as the available loadings, resulting in predicted washoff values that are many times larger than observed. This has the effect of incorrectly assuming greater pollutant contributions originating from streets and less from other areas during rains. This in turn results in inaccurate estimates of the effectiveness of different source area urban runoff controls.

As shown in a summary of much accumulation data from throughout the US, smooth streets had much lower initial loadings immediately after street cleaning, but street texture may not affect particulate accumulations as much as land use.

\section{Acknowledgments}

Many studies are represented in the data presented in this chapter. These were funded, often as part of related stormwater research projects, by several agencies, including the US EPA, Environment Canada, and state and provincial governments (Ontario Ministry of the Environment and Wisconsin, 
for example). The excellent suggestions made by the manuscript reviewers to improve this chapter are also gratefully acknowledged.

\section{References}

Alley, W. M. Determination of the decay coefficient in the exponential washoff equation. International Symposium on Urban Runoff. University of Kentucky. Lexington, KY. July. 1980

Alley, W. M. . Estimation of impervious-area washoff parameters. Water Resources Research. Vol. 17, No. 4, pp 1161-1166. 1981

Andral, M.C.; Roger, S.; Montrejaud-Vignoles, M.; and Herremans, L. Particle Size Distribution and Hydrodynamic Characteristics of Solid Matter Carried by Runoff from Motorways, Water Environ. Res., 71, 4, 398. 1999

American Public Works Association. Water Pollution Aspects of Urban Runoff. Water Pollution Control Research Series WP-20-15. Federal Water Pollution Control Administration. January. 1969

Ball, J.E., Jenks, R., and Auborg, D. Dry Weather Build-up of Constituents on Road Surfaces. Proc. 7th Int. Conf. on Urban Storm Drainage, Hannover, Germany, IAHR/IAWQ Joint Committee on Urban Storm Drainage, 785. 1996

Ball, J.E. Runoff from Road Surfaces - How Contaminated is It? Proc. Hydro 2000 Hydrology and Water Resources Symposium, Perth, WA, Australia. 2000

Bannerman, R., K. M. Baun, P. E. Bohn, and D. A. Graczyk. Evaluation of Urban Nonpoint Source Pollution Management in Milwaukee County, Wisconsin. PB 84114164. U.S. Environmental Protection Agency. Chicago, IL. 1983

Box, G. E. P., W. G. Hunter, and J. S. Hunter. Statistics for Experimenters. John Wiley and Sons. New York, NY. 1978

Burton, G.A. Jr., and R. Pitt. Stormwater Effects Handbook: A Tool Box for Watershed Managers, Scientists, and Engineers. CRC Press, Inc., Boca Raton, FL. 2002. 911 pages.

COE (U.S. Corps of Engineers). Hydrologic Engineering Center. Urban Storm Water Runoff: STORM. Generalized Computer Program. 723-58-L2520. Davis, CA. May. 1975

Dierkes, C., and Geiger, W.F. Pollution Retention Capabilities of Roadside Soils. Water Sci. Technol. (G.B.), 39, 2, 201. 1999

Donigian, A. S., Jr. and N.H. Crawford. Modeling Nonpoint Pollution from the Land Surface. EPA-600/3-76-083. U.S. Environmental Protection Agency. Athens, GA. July. 1976

Downing, S. L. and McGarity, A. E. Wet Weather Pollution Effects on Water Quality in Crum Creek. Proc. Adv. in Urban Wet Weather Pollut. Reduction, Cleveland, Ohio, WEF (CP3805), 473. 1998

Drapper, D.; Tomlinson, R.; and Williams, P. Pollutant Concentrations in Road Runoff: Southeast Queensland Case Study. J. Environ. Eng. 126, 313. 2000

EPA. Results of the Nationwide Urban Runoff Program. Water Planning Division. PB 84185552. Washington, D.C. December. 1983 
Huber, W.C. and J.P. Heaney. The USEPA Storm Water Management Model, SWMM: A ten-year Perspective. Second international Conference on Urban Storm Drainage. Urbana, IL. June. 1981

Jewell, T.K., D.D. Adrian and D.W. Hosmer. Analysis of stormwater pollutant washoff estimation techniques. International Symposium on Urban Storm Runoff. University of Kentucky. Lexington, KY. July. 1980

Kayhanian, M.; Singh, A.; Suverrkropp, C.; Borroum, S. Impact of annual average daily traffic on highway runoff pollutant concentrations. J. Environ. Eng. 129(11):975-990. 2003

Krein, A., and Schorer, M. Road Runoff Pollution by Polycyclic Aromatic Hydrocarbons and its Contribution to River Sediments. Water Res. (G.B.). 34, 4110. 2000

Lau, S.-L.; Ma, J.-S.; Kayhanian, M.; Stenstrom, M.K. First flush of organics in highway runoff. Global Solutions for Urban Drainage, Proc. of the Ninth Int. Conf. on Urban Drainage, Sept 8-13 2002, Portland, OR, CD-ROM. 2002

Ma, J.-S.; Khan, S.; Li, Y.-X.; Kim, L.-H.; Ha, S.; Lau, S.-L.; Kayhanian, M.; Stenstrom, M.K. First flush phenomena for highways: How it can be meaningfully defined. Global Solutions for Urban Drainage, Proc. of the Ninth Int. Conf. on Urban Drainage, Sept 813 2002, Portland, OR, CD-ROM. 2002

McCrone, W.C., Draftz, R.G., Delly, and J.G.: The Particle Atlas, Ann Arbor Science Publishers, Inc., Ann Arbor, Michigan, 1967

Mishra, S.K.; Sansalone, J.J.; Singh, V.P. Hysteresis-based analysis of overland metal transport. Hydrol. Process. 17(8):1579-1606. 2003

Montrejaud-Vignoles, M., Roger, S., and Herremans, L. Runoff water pollution of motorway pavement in Mediterranean area. Proc. 7th Int. Conf. on Urban Storm Drainage, Hannover, Germany, IAHR/IAWQ Joint Committee on Urban Storm Drainage, 247. 1996

Neary, V.S.; Neel, T.C.; Dewey, J.B. Pollutant washoff and loading from parking lots in Cookeville, Tennessee. Global Solutions for Urban Drainage, Proc. of the Ninth Int. Conf. on Urban Drainage, Sept 8-13 2002, Portland, OR, CD-ROM. 2002

Novotny, V. and G. Chesters. Handbook of Nonpoint Pollution Sources and Management. Van Norstrand Reinhold Company. New York, NY. 1981

Pitt, R. and G. Amy. Toxic Materials Analyses of Street Surface Contaminants, EPA-R273-283, U.S. Environmental Protection Agency, Washington, D.C. 134 pgs. 1973.

Pitt, R. Demonstration of Nonpoint Pollution Abatement Through Improved Street Cleaning Practices. EPA-600/2-79-161. U.S. Environmental Protection Agency. Cincinnati, OH. August. 1979

Pitt, R. and G. Shawley. A Demonstration of Non-Point Source Pollution Management on Castro Valley Creek. Alameda County Flood Control and Water Conservation District (Hayward, CA) for the Nationwide Urban Runoff Program. U.S. Environmental Protection Agency. Water Planning Division. Washington, D.C. June. 1982

Pitt, R. and R. Sutherland. Washoe County Urban Stormwater Management Program, Washoe Council of Governments, Reno, NV, August 1982.

Pitt, R. Urban Bacteria Sources and Control in the Lower Rideau River Watershed. Ottawa, Ontario. Ontario Ministry of the Environment. ISBN 0-7743-8487-5. 165 pgs. 1983

Pitt, R. Characterizing and Controlling Urban Runoff through Street and Sewerage Cleaning. U.S. Environmental Protection Agency. Storm and Combined Sewer 
Program. Risk Reduction Engineering Laboratory. EPA/600/S2-85/038. PB 85186500. Cincinnati, OH. June. 1985

Pitt, R. and J. McLean. Toronto Area Watershed Management Strategy Study. Humber River Pilot Watershed Project. Ontario Ministry of the Environment. Toronto, Ontario. 1986

Pitt, R. Small Storm Urban Flow and Particulate Washoff Contributions to Outfall Discharges. Ph.D. dissertation submitted to the Department of Civil and Environmental Engineering. University of Wisconsin - Madison. 1987

Roger, S.; Montrejaud-Vignoles, M.; Adral, M. C.; Herremans, L.; and Fortune, J. P. Mineral, Physical and Chemical Analysis of the Solid Matter carried by Motorway Runoff Water. Water Res. (GB), 32, 4, 1119. 1998

Sansalone, J.J., and Buchberger, S.G. Characterization of Solid and Metal Element Distributions in Urban Highway Stormwater. Proc. 7th Int. Conf. on Urban Storm Drainage, Hannover, Germany, IAHR/IAWQ Joint Committee on Urban Storm Drainage, 253. 1996

Sartor J. and G. Boyd. Water Pollution Aspects of Street Surface Contaminants. EPA-R272-081, U.S. Environmental Protection Agency. November, 1972

Shaheen, D.G. Contributions of Urban Roadway Usage to Water Pollution. 600/2-75-004. U.S. Environmental Protection Agency. Washington, D.C. April. 1975

Sharma, M.; Mcbean, E. A.; and Marsalek, J. Source Characterization of Polycyclic Aromatic Hydrocarbons in Street and Creek Sediments. Water Qual. Res. J. Canada, 32, 1, 23. 1997

Shinya, M.; Tsuruho, K.; Konishi, T.; Ishikawa, M. Evaluation of factors influencing diffusion of pollutant loads in urban highway runoff. Water Sci. Technol. 47(7-8):227232. 2003

Stenstrom, M.K.; Lau, S.-L.; Lee, H.-H.; Ma, J.-S.; Ha, H.; Kim, L.-H.; Khan, S.; and Kayhanian, M. First Flush Stormwater Runoff from Highways. Proc. ASCE EWRI Conf. - Bridging the Gap: Meeting the World's Water and Environmental Resources Challenges. CD-ROM. 2001

Sutherland, R., and R.H. McCuen. Simulation of urban nonpoint source pollution. Water Resources Bulletin. Vol. 14, No. 2, pp 409-428. April. 1978

Sutherland, R.A.; Tack, F.M.G.; Tolosa, C.A.; and Verloo, M.G. Operationally Defined Metal Fractions in Road Deposited Sediment, Honolulu, Hawaii. J. Environ. Qual. 29, 1431. 2000

Sutherland, R.A. Lead in grain size fractions of road-deposited sediment. Environ. Pollut. 121(2):229-237. 2003

Vaze, J.; Chiew, F.H.S. Study of pollutant washoff from small impervious experimental plots. Water Resour. Res. 39(6):[np]. 2003

Wada, Y., Miura, H., and Muraoka, O. Influence of Discharge Pollutants from the Highway at Rainfall on Water Quality of the Public Water Body. Proc. 7th Int. Conf. on Urban Storm Drainage, Hannover, Germany, IAHR/IAWQ Joint Committee on Urban Storm Drainage, 461. 1996

Waschbusch, R J., Selbig, W.R., and Bannerman, R.T. Sources of phosphorus in Stormwater and Street Dirt form Two Urban Residential Basins in Madison, Wisconsin, 1994-95, U.S. geological Survey Water - Resources Investiga5tion Report 99-4021, 47 p, 1999. 
